OPEN ACCESS

Edited by:

Sylvia Anton,

Institut National de la Recherche

Agronomique (INRA), France

Reviewed by:

Francesca Carella,

University of Naples Federico II, Italy

Amir Ayali,

Tel Aviv University, Israel

*Correspondence:

Paul L. R. Andrews

pandrews@sgul.ac.uk

${ }^{\dagger}$ Equal first authors.

Specialty section

This article was submitted to Invertebrate Physiology, a section of the journal

Frontiers in Physiology

Received: 28 February 2017

Accepted: 27 June 2017

Published: 17 July 2017

Citation:

Sykes AV, Almansa E, Cooke GM Ponte G and Andrews PLR (2017) The

Digestive Tract of Cephalopods: a

Neglected Topic of Relevance to

Animal Welfare in the Laboratory and

Aquaculture. Front. Physiol. 8:492.

doi: 10.3389/fphys.2017.00492

\section{The Digestive Tract of Cephalopods: a Neglected Topic of Relevance to Animal Welfare in the Laboratory and Aquaculture}

\author{
António V. Sykes ${ }^{1 \dagger}$, Eduardo Almansa ${ }^{2 \dagger}$, Gavan M. Cooke ${ }^{3}$, Giovanna Ponte ${ }^{4,5}$ and \\ Paul L. R. Andrews ${ }^{4,5 *}$ \\ ${ }^{1}$ Centro de Ciências do Mar do Algarve, Universidade do Algarve, Faro, Portugal, ${ }^{2}$ Centro Oceanográfico de Canarias, \\ Instituto Español de Oceanografía, Santa Cruz de Tenerife, Spain, ${ }^{3}$ Department of Life Sciences, Anglia Ruskin University, \\ Cambridge, United Kingdom, ${ }^{4}$ Association for Cephalopod Research (CephRes), Naples, Italy, ${ }^{5}$ Department of Biology and \\ Evolution of Marine Organisms, Stazione Zoologica Anton Dohrn, Villa Comunale, Naples, Italy
}

Maintenance of health and welfare of a cephalopod is essential whether it is in a research, aquaculture or public display. The inclusion of cephalopods in the European Union legislation (Directive 2010/63/EU) regulating the use of animals for scientific purposes has prompted detailed consideration and review of all aspects of the care and welfare of cephalopods in the laboratory but the information generated will be of utility in other settings. We overview a wide range of topics of relevance to cephalopod digestive tract physiology and their relationship to the health and welfare of these animals. Major topics reviewed include: (i) Feeding cephalopods in captivity which deals with live food and prepared diets, feeding frequency (ad libitum vs. intermittent) and the amount of food provided; (ii) The particular challenges in feeding hatchlings and paralarvae, as feeding and survival of paralarvae remain major bottlenecks for aquaculture e.g., Octopus vulgaris; (iii) Digestive tract parasites and ingested toxins are discussed not only from the perspective of the impact on digestive function and welfare but also as potential confounding factors in research studies; (iv) Food deprivation is sometimes necessary (e.g., prior to anesthesia and surgery, to investigate metabolic control) but what is the impact on a cephalopod, how can it be assessed and how does the duration relate to regulatory threshold and severity assessment? Reduced food intake is also reviewed in the context of setting humane end-points in experimental procedures; (v) A range of experimental procedures are reviewed for their potential impact on digestive tract function and welfare including anesthesia and surgery, pain and stress, drug administration and induced developmental abnormalities. The review concludes by making some specific recommendations regarding reporting of feeding data and identifies a number of areas for further investigation. The answer to many of the questions raised here will rely on studies of the physiology of the digestive tract.

Keywords: cephalopods, digestive tract, Directive 2010/63/EU, Octopus vulgaris, Sepia officinalis, welfare 


\section{INTRODUCTION}

Normal development, growth and the maintenance of health and well-being are only possible if all the digestive tract functions (e.g., motility, digestion, and absorption) operate normally and in concert. Understanding the physiological processes and the impact of external factors (e.g., handling, temperature, diet quality including exposure to food toxins, exposure to viral/bacterial infections and parasites) is important for normal laboratory maintenance of the animal in a research setting, as well as for optimizing conditions for aquaculture at each life stage.

The study of the physiology of the cephalopod digestive apparatus has mainly focused on Sepia officinalis (Bidder, 1966; Boucaud-Camou and Boucher-Rodoni, 1983; Mangold and Bidder, 1989; Quintela and Andrade, 2002a,b; Sykes et al., 2013; Costa et al., 2014), Octopus vulgaris (Boucher-Rodoni and Mangold, 1977; Boucaud-Camou and Boucher-Rodoni, 1983; Andrews and Tansey, 1983b; Mangold and Bidder, 1989), Octopus maya (Martínez et al., 2011a,b, 2012; Rosas et al., 2013; Linares et al., 2015; Pech-Puch et al., 2016). Few studies have been carried out in Loligo vulgaris and other squid (Bidder, 1950; Mangold and Bidder, 1989). Furthermore, the morphology, motility and absorptive functions of the digestive tract of Nautilus pompilius have been the subject of limited investigation (Westermann and Schipp, 1998a,b, 1999; Ruth et al., 1999; Westermann et al., 2000, 2002).

The inclusion of all "live cephalopods," taken to mean all living species (about 700), at all life stages after hatching, in Directive 2010/63/EU (European Parliament and Council of the European Union, 2010) covering the use of animals in scientific research and education poses a number of challenges for research (Smith et al., 2013; Fiorito et al., 2015) including that aimed at optimizing practices in aquaculture (Sykes et al., 2012; Smith et al., 2013; Fiorito et al., 2015). Whilst the Directive regulates studies in the Member States of the European Union, the principles it enshrines and the approaches to care and welfare required for compliance are likely to impact on cephalopod research outside the European Union (see Fiorito et al., 2014, for discussion of wider implications). In comparison to the commonly studied vertebrate laboratory species and commercially exploited vertebrates such as salmon and trout, chickens, cows, and pigs (Stevens, 1988; Grosell et al., 2010; Rønnestad et al., 2013), knowledge of the physiology of the cephalopod digestive tract at all life stages is limited.

Cephalopods are also kept for education and display purposes and, as in the laboratory and aquaculture, the normal functioning of the digestive tract is essential for good health and wellbeing (Fiorito et al., 2015). In this review, we will highlight a number of specific aspects of the relationship between feeding behavior and the physiology of the cephalopod digestive tract where increased understanding is required to ensure animal welfare. We will also discuss areas where further study is required.

\section{FEEDING CEPHALOPODS IN CAPTIVITY}

The vast majority of known cephalopods are carnivorous, obtaining food either by scavenging (e.g., N. pompilius) or predation of live food (e.g., S. officinalis, L. vulgaris, O. vulgaris), with a few exceptions such as the vampire squid (Vampyroteuthis infernalis) that is a detritivore of "marine snow," possibly requiring different digestive processes to obligate cephalopod carnivores (Hoving and Robison, 2012).

Information on diets in the wild is limited, but insights can be obtained through analysis of isotopes or stomach contents among other techniques (e.g., Hobson and Cherel, 2006; Villegas et al., 2014; Scheel et al., 2016; Regueira et al., 2017). In captivity, individual animals may show a preference for one type of prey over another even when both are available (e.g. crustaceans vs. fish for S. officinalis, crustaceans vs. mussels for O. vulgaris). Captive conditions, especially during key developmental periods may influence food preference across the life of an individual, as seen for example in cuttlefish (Darmaillacq et al., 2008). Nevertheless, most of the species adapt well to the laboratory and the diet may be narrowed to a few selected items (see Fiorito et al., 2015).

\section{Live Food and Prepared Diets}

The provision of live food (mostly commonly crustaceans, mussels, or small fish) to captive cephalopods is the most common practice. It is normally based on freshly caught (when applicable) items, that are not subjected to nutritional decay (e.g., oxidation in frozen food) as it may affect the growth of the cephalopod (Correia et al., 2008a,b). Live food greatly increases husbandry requirements as most cephalopods require crustaceans which produce higher levels of waste material (i.e., exoskeleton material containing uneaten soft tissues), thus potentially affecting water quality in tanks; this puts an additional burden on filtration systems and cleaning logistics. Providing live food also raises ethical issues as the death of the prey may not be humane, especially if it has the potential to suffer as fish are assumed to (Sneddon, 2015), and decapod crustaceans (Barr et al., 2008) may do.

Cephalopods are likely to have been exposed to parasites or toxins from their diet in the wild, however concern in the use of live food for laboratory housed animals may be also taken into account because of the hypothetical risk posed by introduction through the food given.

Contrarily, the use of live food is simply neither practical nor economical in production scale aquaculture so there is a considerable research effort into the development of prepared diets (Iglesias et al., 2014; Martínez et al., 2014; Cerezo Valverde and García, 2017). If successful, these alternative feeds would also possibly become a standard in the laboratory and public aquaria.

Although prepared diets may be cheaper, are likely to be more convenient and have a lower potential infection risk than live food, there is an argument that the provision (possibly intermittently) of live or frozen prey as food can be considered as "enrichment" for the cephalopod and hence beneficial for overall welfare (Cooke and Tonkins, 2015; see review in Fiorito et al., 2015). The importance of environmental ("tank") enrichment in animal experimentation (Bayne and Würbel, 2014; Yasumuro and Ikeda, 2016) and aquaculture (Ashley, 2007; Martins et al., 2012; Näslund and Johnsson, 2016) is being increasingly appreciated. 


\section{Feeding Frequency and the Amount of Food Provided}

In the wild, the frequency of food intake in a cephalopod is considered to be influenced by multiple factors including: the availability of prey; the ability of the animal to locate and catch the prey (this will be affected by its health status); the time taken to ingest the prey and any pre-absorptive satiety signals (e.g., crop or stomach distension via mechanosensitive afferents if they exist in cephalopods); the time taken to digest the prey, absorb the nutrients and eliminate waste (all likely to be affected by any digestive tract pathology; see below) together with any post-absorptive satiety signals; the size, amount and nutritional value of the prey; the metabolic rate of the animal; activity level; environmental temperature and seasonality; life stage and sexual maturity.

Food availability and seawater temperature are considered to be the major factors influencing growth of cephalopods (Semmens et al., 2004). However, even if these parameters are optimal with respect to animal needs, if the digestive tract is in a pathophysiological state, food utilization will be affected with negative impact on bodily maintenance, growth and overall health.

In the laboratory or other captive settings, feeding frequency and amount of food provided may also considered within the framework of the "Five Freedoms" principle outlining minimal welfare standards (http://ec.europa.eu/food/animals/ welfare_en; Huntingford, 2008). One of the "Freedoms" states that animals should be "free from hunger" (www.rspca.co. uk/education). It is not known if cephalopods experience a sensation of hunger, or a functionally equivalent sensation, comparable to that in humans. Tracking the behavioral changes such as latency and time to attack, following a large meal ("satiety") to the time when the meal has been fully digested (presumed presence of "hunger") will provide insights into the frequency with which food should be provided to minimize the possibility of unpleasant sensations arising from lack of food (i.e., hunger). Below we will focus on two modalities of providing food to animals: ad libitum and intermittent.

Ad libitum feeding is usually taken to mean that the animal has access to an "excess" amount of food at all times so that in principle it can eat to satiety (or potentially over feed) whenever it requires. However, few studies define what they mean by ad libitum. Even when the frequency of food provision is stated the amount provided is not, making comparison of regimes difficult. For example, an ad libitum regime in juvenile S. officinalis is provided in some settings by live grass shrimp (Palaemonetes varians) given twice daily although the amount given is not specified (Gonçalves et al., 2012). Examples of species in which feeding described as ad libitum feeding has been used include: for sepiolid, Euprymna tasmanica, (live mysids, Moltschaniwskyj and Johnston, 2006); for cuttlefish, S. officinalis, (live and frozen grass shrimp, Sykes et al., 2013); for octopus, O. vulgaris, live crabs (e.g., Agnisola et al., 1996); for O. maya (frozen crabs, Linares et al., 2015). Ad libitum feeding is achieved by placing food in the tank to allow the animals free access, with sufficient food provided to last until replenished.
An alternative may be to re-examine the utility of automated food dispensers previously investigated for example for feeding O. vulgaris (Nixon, 1969). Such automated methods could easily be applied to pelleted diets (artificial or synthetic) and would allow the feeding pattern to be studied which will be essential for investigating the neural and hormonal mechanisms controlling food intake and digestion. With a food dispenser there is a possibility that the animal will access, but not eat food, increasing wastage and tank contamination. Additionally, animals housed in groups (e.g., O. vulgaris in some aquaculture settings) may compete for access to the dispenser. There is also a possibility that the animal (particularly octopuses) will damage the food dispenser or may damage themselves on the food dispenser.

For aquaculture, ad libitum feeding will be necessary to ensure fastest growth rates although the health and welfare consequences (if any) of such regimes require study. However, it is reported that it is impossible to over feed a cephalopod and that they will reject excess food, but the evidential basis for this appears unclear (Boucaud-Camou and Boucher-Rodoni, 1983) although it is consistent with the experience of one of the authors of this review (AS).

Intermittent feeding applies to conditions where a given amount of food is provided to the animal which it will consume in one "meal" and it is most commonly applied to providing food either daily (e.g., grass shrimp for Abdopus aculeatus, Alupay et al., 2014; pieces of fish for O. vulgaris, Matzner et al., 2000; García García et al., 2011), more frequently (e.g., frozen squid twice daily for O. vulgaris, Garcia-Garrido et al., 2010) or less frequently (e.g., a crab every second day in O. vulgaris, Boucher-Rodoni and Mangold, 1985; shore crab twice weekly in S. officinalis, Wearmouth et al., 2013). Food is not available at all times but obviously if the amount of food provided is greater than can be ingested in a single meal then in effect food is provided ad libitum. For example, in Octopus maya animals given one small $\mathrm{crab} / 50 \mathrm{~g}$ body weight daily ate all the crab, but if two crabs/50 $\mathrm{g}$ body weight were provided at the same time animals did not ingest all the crab (Walker et al., 1970). The literature also has examples of feeding an individual "meal," but providing food on multiple occasions during the day. For example, Yacob et al. (2011) report feeding S. officinalis on frozen shrimp and live zebra fish twice daily and in another cuttlefish study animals were fed frozen krill and silversides by hand 3-4 times a day (Tressler et al., 2014).

A further example of issues relating to the description of feeding regimes is provided by a study of O. vulgaris which comments, "octopuses were fed once per day to satiation with filet of frozen bogue (Boops boops)" (García García et al., 2011, p. 162). It is presumed that satiety was indicated by the refusal to take further food when offered but it would not necessarily be known if the animals would eat again if offered food prior to the next day. If the term "satiety" is used it would be helpful to have an indication of the criteria on which the assessment was made.

It is evident that the Methods sections of publications do not always give sufficient information either for the feeding regime to be replicated or to enable valid inter-study comparison. In view of this we would recommend that as a minimum the Authors should specify: the type of food provided (e.g., live, freshly killed, 
previously frozen, processed/prepared); the amount provided (weight, including for live food; see Methods in Lamarre et al., 2012, for an example); the frequency of feeding and the time at which the food was provided.

For example, Garcia-Garrido et al. (2010) report feeding $O$. vulgaris on frozen squid (Loligo gahi) given at two times (9 a.m. and 3 p.m.), with the total amount of food provided daily being $5 \%$ of the body weight of the octopus. Ideally the energy density and chemical composition of the diet should also be given (for an example see Estefanell et al., 2011) or a reference provided to previous studies where similar food has been provided.

\section{Food Amount}

Despite the diverse feeding regimes and paucity of detail in much of the literature, a number of publications have undertaken detailed studies of the feeding requirements of several species (e.g., O. vulgaris, Estefanell et al., 2011; Octopus tetricus, Joll, 1977; S. officinalis, Domingues et al., 2001). Feeding requirements of a particular species, at a particular life stage and temperature are usually given as the weight of food as a percentage of body weight. The latter assumes the energy density of the food is sufficient to meet all the calorie and nutrient requirements and micronutrients. However, not all diets are equivalent. For example, in adult $O$. vulgaris growth rate is lower when they are fed ad libitum exclusively on sardines compared with squid or crab (Quintana et al., 2015). One reason to explain this difference could be the high neutral lipid content of sardines. Cephalopods seem to have a low capability to digest neutral lipids due to the absence of lipid emulsifiers in their digestive tracts (Vonk, 1962; O'dor et al., 1984; Morillo-Velarde et al., 2015).

For a particular diet, under well-defined environmental conditions (particularly temperature) it should be possible to give guidance on the amount of food required daily for a given species and life stage. This approach is illustrated by the study of Garcia-Garrido et al. (2010) in which O. vulgaris juveniles were fed $5 \%$ of their body weight daily on a diet of frozen squid or by the studies of Castro et al. (1993), Castro and Lee (1994), and Domingues et al. (2008), where S. officinalis were fed $\approx 8 \%$ of their body weight daily on shrimp species (either Palaemon or Palaemonetes).

As publications adopt a more systematic and detailed approach to describing diets in the methods sections it will be possible to undertake meta-analyses of the dietary data and provide stronger evidence based guidance on the amount of a particular food to provide.

Studies of feeding regimes are currently driven mainly by the aquaculture potential of cephalopods and the requirement to either develop artificial diets (Iglesias et al., 2014; Vidal et al., 2014) or to optimize natural diet formulations (e.g., ratio of fish to crab for O. vulgaris; García-García and Cerezo-Valverde, 2006). It is essential that the diet provided in the laboratory, aquaculture or public aquaria fulfills all the nutritional requirements of the animal, including micronutrients (Navarro et al., 2014). In this context, studies comparing metabolism of animals fed natural and artificial diets are of particular relevance (e.g., O. maya, Rosas et al., 2007). Studies of food intake and growth can be supplemented by measurements of haemolymph protein, amino acids and long chain polyunsaturated fatty acids (Linares et al., 2015), digestive enzymes (e.g., Villanueva et al., 2002) or body composition to provide an objective assessment of metabolic status (Garcia-Garrido et al., 2010; Navarro et al., 2014; Linares et al., 2015).

\section{Particular Challenges in Feeding Hatchlings and Paralarvae}

Cephalopods do not undergo metamorphosis like fish larvae (Young and Harman, 1988) but several species have a first life stage that starts with hatching and lasts until all its systems mature, including the digestive tract. Nonetheless, as in fish (Zambonino-Infante and Cahu, 2001), this period of maturation is normally a period of a month, depending on seawater temperature (Moguel et al., 2010; Sykes et al., 2013; Iglesias and Fuentes, 2014), and has been identified as a recurrent bottleneck for the development of cephalopod aquaculture (Sykes et al., 2006; Villanueva et al., 2014). Despite the multitude of reproductive strategies that cephalopods display (Rocha et al., 2001), the first life stage after hatching is usually termed "paralarvae" for species that undergo indirect embryonic development, and "hatchlings" for those which display direct development. These differences in development correspond to differences in the number and size of eggs laid by females (higher in indirect development species, e.g., O. vulgaris) and the relative "degree" of development at hatching (higher in direct development species, e.g., S. officinalis, O. maya; Boletzky, 1981, 1986). This is the key point leading to particular challenges regarding welfare of paralarvae and hatchlings in both the laboratory and aquaculture. In both cases (either paralarvae and hatchlings), cephalopods kept under captivity hatch with inner yolk reserves (Boletzky, 1994) that may last for days or weeks depending on temperature and proper food availability, as they display a mixed embryonic and postembryonic nutrition (Boletzky and Villanueva, 2014). Despite the differences in size at hatching, neither paralarvae nor the hatchlings display a prey ingestion problem related to the size of the "mouth," as that reported for finfish (Yúfera and Darias, 2007). However, the use of any feeds, other than live prey, during this first life stage (Sykes et al., 2014) limits growth and development, and eventually will impact welfare, (Navarro and Villanueva, 2000; Sykes et al., 2013).

\section{PARASITES AND TOXIN LOAD OF THE CEPHALOPOD DIGESTIVE TRACT: POSSIBLE IMPACT ON ANIMAL WELFARE AND CONFOUNDING VARIABLES IN EXPERIMENTAL DESIGN}

The wild remains the main source for cephalopods used in research so there is a realistic possibility that animals in the laboratory may have parasites in the digestive tract. Parasites are of concern for several reasons including, the impact on the overall health and welfare of the animal (Sykes and Gestal, 2014), as a source of infection for other animals (including humans unless precautions are taken, see Fiorito et al., 2015), and as a confounding factor in an experiment. 
The digestive tract parasite Aggregata octopiana (Protozoa: Apicomplexa) is considered to be one of the main epizootic agent in both wild and reared O. vulgaris and exemplifies some of the issues. The intermediate host for this coccidian are crustaceans that form part of the normal diet for O. vulgaris. Aggregata is reported to cause loss of epithelial cells, mucosal atrophy and inflammation in the caecum and intestine resulting in impaired body growth, proposed to all be due to intestinal malabsorption syndrome (Gestal et al., 2002a,b). The prevalence of $A$. octopiana is high and reported to reach $98 \%$ (Gestal et al., 2002a) in the local population (Vigo, Spain). Although it is possible to count the number of sporocysts to assess the presence and magnitude of infection (Castellanos-Martinez et al., 2014) this requires death of the animal and removal of gut tissue, so it is not currently possible to assess the presence of Aggregata at the time animals are allocated to an experimental group. Whilst random allocation should reduce the potential for inadvertently assigning animals with high and low levels of infection to "control" and "test" groups for an experiment, it is possible that including groups with some infected animals may increase the variability within the group, potentially leading to a false negative result from statistical testing. In addition, the variability will affect the validity of any power calculation used to estimate group size in experimental design if the estimated effect size is influenced by the parasitic infection.

In theory, it should be possible to identify animals infected with Aggregata by looking for sporocysts in the feces of living animals prior to allocation to study groups, but this possibility has not been explored in published accounts, to the best of our knowledge. In O. vulgaris, it may also be possible to inspect the terminal intestine for sporocysts by gentle retraction of the ventral mantle or by endoscopy. Until techniques are available for in vivo assessment of Aggregata status or for its eradication prior to experiment it is probably wise to assume a high prevalence of infection in animals caught from the wild, unless there is evidence to the contrary in a local population used by a particular laboratory. We recommend that as a minimum the digestive tract is carefully examined macroscopically post mortem for the presence of sporocysts, particularly in the caecum and intestine but they may also be visible in the crop. Ideally the number of Aggegata sporocysts should be counted so that the magnitude of any infection can be investigated for correlation with experimental parameters to build up a profile of its biological effects. Once the spectrum of effects of Aggregata infection is known it will then be possible to make an informed assessment about its role as a confounding factor in experiments.

Whilst we have focused on Aggregata as a potential confounding factor in research we should not overlook the fact that animals with any infection may have a lower health status than those without and this raises a broader question of whether animals with Aggregata should ever be used in research studies other than those studying the effects of Aggregata itself.

We have used the infection of the digestive tract by Aggregata to illustrate one potential problem with using wild caught animals but we should also consider the digestive tract flora. The digestive tract microbiome and its role in health and disease has been the subject of detailed investigation in mammals but studies of the digestive tract flora are required in cephalopods. We mention the digestive tract microbiome here in relation to welfare as when animals are transferred from the wild to the laboratory, possibly involving a change of diet, it is highly likely that the flora in the digestive tract will change with as yet unknown effects on the functionality of the digestive tract and overall animal health. In addition, the impact of feeding prepared diets on the digestive tract flora of either wild caught or laboratory bred animals is not known.

A final factor to consider is the impact of any toxins that the animal may have been exposed to in the wild and which gain access to the body via the digestive tract. To illustrate this point we will use as examples shellfish toxins produced by phytoplankton species, ingested by bivalves which are subsequently ingested by benthic cephalopods. Domoic acid is responsible for amnesic shellfish poisoning in mammals (Pulido, 2008; Lefebvre and Robertson, 2010) and several compounds (e.g., saxitoxin, neosaxitoxin, gonyautoxins) are responsible for paralytic shellfish poisoning (Lopes et al., 2013). In mammals, these shellfish toxins have acute onset ( $<24 \mathrm{~h}$ ) neurological (e.g., amnesia and locomotor paralysis) and gastrointestinal (nausea, vomiting and diarrhea) effects (for reviews see Lefebvre and Robertson, 2010; Visciano et al., 2016).

In cephalopods, although there are reports of mass stranding of Humboldt squid (Dosidicus gigas; Lopes et al., 2013) attributed to paralytic shellfish toxins (PST), we were unable to find any reports of acute onset effects of PSTs. In a study of PSTs in O. vulgaris, Lopes et al. (2014) comment (p. 210), “Despite of the remarkably high levels of toxins detected no apparent harm neither signs of behavioral changes were observed."

For the amnesic shellfish toxin domoic acid reports of acute effects are also lacking, an observation that is particularly intriguing as glutamate is known to be a neurotransmitter in both central and peripheral neural tissues in cephalopods (Messenger, 1996). Both domoic acid and PSTs have been shown to accumulate in the digestive gland of $O$. vulgaris (Costa and Pereira, 2010; Lopes et al., 2014) but the effects of these toxins on digestive gland function or other tissues is not known. Animals caught from the wild and utilized in research studies are likely to have different digestive gland concentrations of amnesic and paralytic shellfish toxins and these may vary seasonally depending upon algal blooms. The impact of the "toxin load" on health of the animal is unknown and differences in toxin concentration are a possible contributor to experimental variability; research is required to characterize the acute (e.g., brain and digestive tract function) and chronic (e.g., digestive gland metabolism, animal growth, and ability to withstand infection) physiological effects of amnesic and paralytic shellfish toxins on the cephalopods commonly studied in the laboratory.

\section{FOOD DEPRIVATION AS A COMPONENT OF RESEARCH INVESTIGATIONS}

There are several situations in research when it may be considered necessary to deliberately deprive the animal of food. Here we consider the justification for food deprivation in 
different contexts and also the duration of such deprivation within the framework of regulated procedures under Directive 2010/63/EU (European Parliament and Council of the European Union, 2010).

\section{Transportation}

Accumulation of toxic ammonia from renal excretion arising primarily from protein metabolism (García García et al., 2011) and fecal contamination are a risk when transporting cephalopods in non-circulating sea water resulting in acidification. Depending upon the transport distance, species and size of the animal food deprivation should be considered and may be combined with transport in water at a temperature below ambient to reduce metabolic rate and carbon dioxide production (Fiorito et al., 2015).

There are no specific recommendations for the duration of food deprivation for each species as this will depend upon the normal feeding frequency, diet and digestive tract transit time. It is unlikely that in most cases more than 1-2 days, food deprivation is necessary to void the digestive tract of food and digesta, with the longer time being more appropriate for species held at lower temperatures where transit time may be slower (Boucaud-Camou and Boucher-Rodoni, 1983; Mangold and Bidder, 1989). It is essential that the duration of any food deprivation prior to transport is scientifically justified and is minimized to avoid compromising health (see below) during what is likely to be a stressful event.

\section{Surgery and Anesthesia}

In humans, deprivation of food prior to anesthesia and surgery is justified because of the risk of aspiration of vomit during induction, before airway intubation and this is also normal practice prior to veterinary or experimental surgery in larger mammals. The justification for routinely depriving cephalopods of food prior to anesthesia and surgery is not established and obviously inspiration of any regurgitated digestive tract contents into the mantle does not pose the same risk to a cephalopod as aspiration of vomit in a mammal. However, there is an argument for food deprivation if the surgical procedure involves the digestive tract itself. A full stomach (e.g., L. vulgaris) or crop (e.g., O. vulgaris) may increase the risk of accidental damage by obscuring other structures (e.g., crop branch of the dorsal aorta) or limiting the plane of dissection, so food deprivation may also be justified although this would only need to be omission of one meal or about $24 \mathrm{~h}$ (Fiorito et al., 2015).

\section{Metabolic Studies}

Laboratory investigation of metabolism can require animals to be deprived of food or may require a reduction in the amount of food provided at each meal. The question arises at what point food deprivation itself, as part of a research study, falls within the definition of a procedure which would be regulated under Directive 2010/63/EU and hence should be included in protocols submitted as part of a project application to the National Competent Authority.

Under Directive 2010/63/EU the threshold for regulation is "any use of an animal covered by the Directive for experimental or other scientific or educational purposes, which may cause the animal pain, suffering, distress or lasting harm equivalent to or higher than that caused by the introduction of a needle in accordance with good veterinary practice." It is clearly not easy to translate this definition into the period for which a cephalopod of any particular species (for example, a highly active $L$. vulgaris vs. relatively slow moving $N$. pompilius) or life stage (e.g., O. vulgaris paralarvae vs. egg bearing female) can be deprived of food before it exceeds the threshold for regulation. Periods of food deprivation of 24-48 h have been used prior to investigating the effect of handling on attack latency $(\approx 24$ h in O. vulgaris; Agnisola et al., 1996), before a feeding experiment (48 h in E. tasmanica; Moltschaniwskyj and Johnston, 2006 ) or prior to a study of anesthesia ( $24 \mathrm{~h}$ in S. officinalis; Gonçalves et al., 2012) based largely upon measures of oro-anal transit time for the species under study and also taking into account normal feeding frequency for the species (see above). In $N$. pompilius a period of 5 days food deprivation was used to stimulate appetite prior to feeding barium sulfate labeled shrimp to measure digestive tract transit (Westermann et al., 2002).

A number of studies have investigated the effects of various periods of food deprivation in S. officinalis, Loligo forbesi, and O. vulgaris on metabolism and these are used to make proposals regarding the regulatory threshold and also humane end points (see below).

The physiological response to food deprivation in both vertebrates and invertebrates has three phases (Lamarre et al., 2016): Phase I - basal metabolism is sustained following a few days food derivation utilizing dietary constituents; Phase II with continued food deprivation mobilization of stored lipids occurs and for cephalopods these are primarily located in the digestive gland. A recent study shows that their role in enabling cephalopods to survive prolonged food deprivation may have been underestimated (see Speers-Roesch et al., 2016); Phase III characterized by protein catabolism, it is considered to be the real indication of starvation as opposed to food deprivation Phases I and II.

Juvenile and adult animals are most likely to be used for research studies requiring food deprivation and for these life stages we propose the following regarding the threshold for regulation; periods of food deprivation that do not exceed the metabolic effects of Phase I should be considered to be below the threshold for regulation as defined by Directive 2010/63/EU (European Parliament and Council of the European Union, 2010) whilst procedures that induce the metabolic changes characteristic of Phases II and III fall within the threshold for regulation and would fall into the mild and moderate prospective severity classes respectively (European Commission, 2013). The work by Lamarre et al. (2012) and Speers-Roesch et al. (2016) did not report any mortality in the prolonged food deprivation studies. However, in a group of $O$. vulgaris (body weight $1618.3 \pm 175.5 \mathrm{~g}$ ) deprived of food there was an overall $10 \%$ mortality with individuals dying by an undetermined cause at 16, 20, and 23 days (Garcia-Garrido et al., 2010). The overall weight loss in the animals that survived the entire 27 days food deprivation was $35 \%$. The possibility that death may 
occur in a food deprivation study would be likely to make the severity grading severe and such studies would require detailed justification of the scientific or other benefits vs. the harms to the animal.

The behavior of animals following prolonged food deprivation is not described in detail but in both O. vulgaris (Wells et al., 1983) and S. officinalis (Lamarre et al., 2016) reduced levels of activity are reported and in the latter there are also problems with buoyancy.
Data from the above metabolic studies can provide a guide to the durations of food deprivation exceeding the threshold for regulation under Directive 2010/63/EU and their severity classification. Table 1 proposes how the physiological consequences of food deprivation could be linked to severity classification. Research will be needed to match the relatively well-defined metabolic changes to behavioral (or other) objective indices of "pain, suffering, distress, and lasting harm."

TABLE 1 | The prospective severity classification of experimental procedures as defined in Directive 2010/63/EU together with proposals for how this could relate to periods of food deprivation in an adult $\mathrm{O}$. vulgaris or S. officinalis in good health at the beginning of the deprivation.

\begin{tabular}{|c|c|c|c|c|}
\hline & Below threshold & Mild & Moderate & Severe \\
\hline $\begin{array}{l}\text { Definition of severity from } \\
\text { EU } 2010^{\star} \text { and EC } 2013^{\star}\end{array}$ & $\begin{array}{l}\text { Does not reach the } \\
\text { regulatory threshold of } \\
\text { causing pain, suffering, } \\
\text { distress or lasting harm } \\
\text { equivalent to, or higher than } \\
\text { that caused by the insertion } \\
\text { of a hypodermic needle in } \\
\text { accordance with good } \\
\text { veterinary practice (EU } \\
\text { 2010) }\end{array}$ & $\begin{array}{l}\text { Likely to cause the animals } \\
\text { to experience short- term } \\
\text { mild pain, suffering or } \\
\text { distress as well as } \\
\text { procedures with no } \\
\text { significant impairment of the } \\
\text { well-being or general } \\
\text { condition of the animals (EC } \\
\text { 2013) }\end{array}$ & $\begin{array}{l}\text { Likely to cause the animals } \\
\text { to experience short- term } \\
\text { moderate pain, suffering or } \\
\text { distress as well as } \\
\text { procedures that are likely to } \\
\text { cause moderate impairment } \\
\text { of the well-being or general } \\
\text { condition of the animals (EC } \\
\text { 2013) }\end{array}$ & $\begin{array}{l}\text { Likely to cause the animals } \\
\text { to experience severe pain, } \\
\text { suffering or distress or } \\
\text { long-lasting moderate pain, } \\
\text { suffering or distress as well } \\
\text { as procedures that are likely } \\
\text { to cause severe impairment } \\
\text { of the well-being or general } \\
\text { condition of the animals (EC } \\
\text { 2013) }\end{array}$ \\
\hline
\end{tabular}

\begin{tabular}{|c|c|c|c|c|}
\hline Duration of food deprivation & $0-48 \mathrm{~h}(0-2 \mathrm{~d})^{\star \star}$ & $48-120 \mathrm{~h}(2-5 \mathrm{~d})^{+}$ & $120-288 \mathrm{~h}(5-12 \mathrm{~d})^{+}$ & $>288 \mathrm{~h}(>12 \mathrm{~d})$ \\
\hline Anticipated body weight & $0 \leq 5 \%$ & $<10 \%$ & $\sim 10-15 \%$ & $>15 \%$ \\
\hline
\end{tabular}

loss (\%) (based on
Garcia-Garrido et al., 2010)

\begin{tabular}{|c|c|c|c|c|}
\hline $\begin{array}{l}\text { Anticipated digestive gland } \\
\text { weight loss (\%) (based on } \\
\text { Garcia-Garrido et al., 2010) }\end{array}$ & $0-30 \%$ & $30-50 \%$ & $50-60 \%$ & $>60 \%$ \\
\hline
\end{tabular}

\begin{tabular}{|c|c|c|}
\hline Metabolic phase & Early Phase I & $\begin{array}{l}\text { Late Phase I-early Phase II } \\
\text { (Speers-Roesch et al., } \\
\text { 2016, "middle phase") }\end{array}$ \\
\hline
\end{tabular}

\section{Late Phase II-Early Phase III Phase III- metabolic (Speers-Roesch et al., collapse (Speers-Roesch 2016, "middle phase"-"final et al., 2016, "final phase")} phase")

Metabolic status (Based on Speers-Roesch et al., 2016: Table 1)

Normal metabolism from mixed biochemical sources but by $2-3 d$ signs of a shift from anabolic to catabolic metabolism will emerge
Progressive utilization of lipids from the digestive gland and clear shift from anabolic to catabolic metabolism in the digestive gland.

\section{Anticipated behavioral and} other possible effects
No negative effects anticipated but possible increase in food seeking behavior; experience of hunger sensation?

\section{Progressive reduction in} activity. Adaptive changes in the digestive tract such as upregulation of epithelial transport mechanisms.
Lipid dominant metabolism supplemented by tissue protein catabolism. No glucose utilization.
Dependence on amino acid metabolism with no glucose use and depleted lipid stores
Progressive reduction in activity. Suppression of digestive tract motility.
Overall decline in health; increased susceptibility to infection and skin lesions); potentially irreversible damage to critical tissues (e.g., gills). Death with prolonged deprivation" .

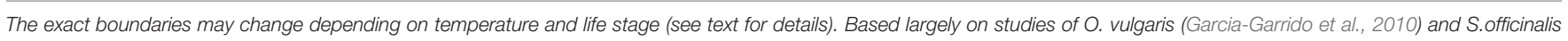

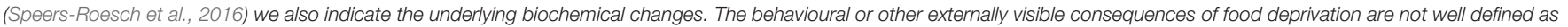

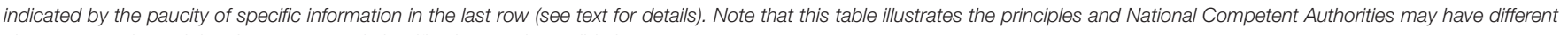
views on severity and the above proposed classification requires validation.

* "EU 2010" and "EC 2013" are abbreviations of European Parliament and Council of the European Union (2010) and European Commission (2013), respectively.

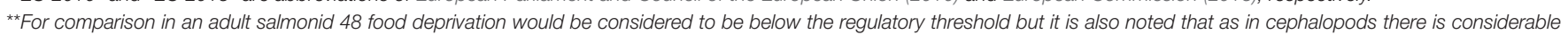
inter-species variation (Hawkins et al., 2011).

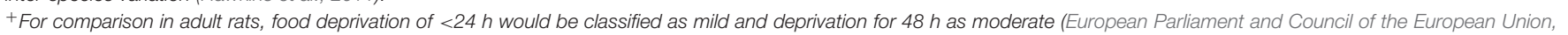
2010).

\#In O. vulgaris Garcia-Garrido et al. (2010) reported death at 16, 20, and 23 days of food deprivation. 
If food deprivation is required for whatever reason, a clear justification should be made both in the application to the National Competent Authority (if the work is covered by Directive 2010/63/EU) and reiterated in any publication. The period of food deprivation should be kept to the minimum compatible with achieving the stated objectives and the impact on all aspects of the animals' health should be carefully assessed (see ARRIVE reporting guidelines; https://www.nc3rs.org.uk/ sites/default/files/documents/Guidelines/NC3Rs\%20ARRIVE $\% 20$ Guidelines\%202013.pdf). In the case of prolonged food deprivation (e.g., Lamarre et al., 2012), the fate of the animal at the end of the period of deprivation will need to be considered and specified in the application to the National Competent Authority (NCA) in research performed under Directive 2010/63/EU (European Parliament and Council of the European Union, 2010). Whilst it is possible that after an extended period of food deprivation the animals may regain body weight when sufficient food is available, the welfare of the animal during this recovery period must be carefully assessed and there should be some assurance that the period of deprivation did not have irreversible effects such as structural protein or lipid loss in critical tissues (brain, heart, and gills) that may cause persistent suffering to the animal.

\section{THE DIGESTIVE TRACT AS A ROUTE FOR SUBSTANCE ADMINISTRATION}

Drug administration by gavage has been used in squid (Berk et al., 2009) and could be used in cuttlefish and octopus although we are not aware of any publications. If gavage is used, care must be taken to taken to avoid damage to the brain as the gavage tube passes from the beak into the esophagus and then into the crop or stomach depending on species. The tube to be utilized should be semi-rigid and round ended, to prevent mucosal damage; measurements should be made on cadavers to estimate the length to which the tube should be inserted unless this is done using ultrasound assisted in vivo imaging.

Food deprivation is probably advisable to facilitate rapid absorption of any drug and prevent drug/food interaction, but the volume of substance administered should be well within the normal volumes found in the crop or stomach to minimize chances of damage or activation of visceral nociceptors (should they exist in cephalopods). Careful consideration should be given to the drug vehicle to avoid substances likely to damage the mucosa or which themselves have effects on mucosal functions (e.g., changes in $\mathrm{pH}$ that will alter the $\mathrm{pH}$ optimum of digestive enzymes and mucolytics will impair epithelial barrier function).

An alternative to gavage is to include the drug in the food. This route was used for the administration of titanium dioxide nanoparticles to O. vulgaris by feeding the animals on mussels that had been exposed to the nanoparticles (Grimaldi et al., 2013). Inclusion of drugs in the food (e.g., injected into a crab, a mussel, a piece of fish or incorporated into a piece of artificial diet just prior to feeding) provides a non-invasive approach to administration but there are several issues to be considered if a study using this approach is to have a meaningful outcome: (1) Although the total dose of drug in the food is known it may be difficult to know the precise amount ingested by the animal unless there is assurance that no drug has leaked into the water during food capture or ingestion and that the animal has eaten all the food. Microencapsulation of the drug will reduce leakage compared to injecting the drug into the food in solution or mixing as a powder but assessing the ingested does remains problematic; (2) The secretions of the salivary glands injected into the prey during capture and prior to ingestion contains powerful enzymes and a wide array of other bioactive substances (Cornet et al., 2014; Mancuso et al., 2014) so some consideration should be given to whether the drug is likely to be affected by the salivary secretions and rendered ineffective. Degradation of the drug by the salivary secretions could lead to false negative conclusion about drug efficacy in cephalopods; (3) As the food with the drug is likely to come into contact with the suckers, particularly in the peri-oral region, there is a possibility that the animal may reject the food based upon "taste" although micro-encapsulation could be used to prevent direct contact.

In cuttlefish, Darmaillacq et al. (2004) showed induction of a learned aversion to food (crabs) painted with quinine, which is bitter tasting to humans, although we do not know what sensation (if any) it may evoke in cephalopods. If the experimental drug evokes rejection and a learned aversion to that food in a similar manner to quinine (many alkaloids are bitter tasting and are also drugs, e.g., atropine and scopolamine), then it may not be ingested and may induce an aversion to that food if encountered again. A learned aversion leading to avoidance of the food on a subsequent occasion can also be induced if the ingested food causes the animal to be ill. In humans the analogous situation would be a food that induced nausea and vomiting (Andrews and Sanger, 2014).

As it may not be possible to predict if a drug will have an adverse effect on the animal it should not be given in the food most commonly used, otherwise if the animal does develop an aversion maintenance of the normal feeding regime may not be possible.

\section{RESEARCH ON DIGESTIVE PHYSIOLOGY AND DIETS FOR CEPHALOPODS: IMPACT OF DIRECTIVE 2010/63/EU AND OTHER REGULATIONS AND POLICIES}

Directive 2010/63/EU and related mandated minimal recommendations on the accommodation and care of animals, include species specific sections that are relatively detailed for vertebrates, but no equivalent indications are provided for cephalopods. However, the "general section" of the Directive (European Parliament and Council of the European Union, 2010) applies to all species and includes some general principles of feeding (Annex III, 3.4) which we outline here as they are relevant to the subsequent discussion of cephalopod diets.

The key elements included under the heading "Feeding" in the Directive are: 
- Form, content and presentation of the diet should meet the nutritional and behavioral needs of the animal;

- Diet should be palatable and non-contaminated and precautions taken to minimize chemical, physical and microbiological contamination;

- Individual animals should be able to access food, with sufficient space provided to limit competition.

These principles embodied in the Directive and national transposition legislation, are reflected in the Guidelines on the Care and Welfare of Cephalopods (Fiorito et al., 2015), and also included in a simplified version, in the Code of Practice on Housing and Care published by the United Kingdom Home Office (see section on Cephalopods; https://www.gov. $\mathrm{uk} /$ government/publications/code-of-practice-for-the-housingand-care-of-animals-bred-supplied-or-used-for-scientificpurposes).

Directive 2010/63/EU applies to the protection of animals used for scientific purposes but as many aspects of this review also apply to animals in an aquaculture setting we draw attention to the following regulations: Council Directive 98/58/EC on the protection of animals kept for farming purposes (Council of the European Union, 1998); Regulation (EC) $\mathrm{N}^{\circ}$ 882/2004 on official controls performed to ensure the verification of compliance with feed and food law, animal health and animal welfare rules (European Parliament and Council of the European Union, 2004); and Council Regulation (EC) N ${ }^{\circ}$ 1099/2009 on the protection of animals at the time of killing (Council of the European Union, 2009).

The identification of optimal dietary formulations (natural or synthetic) for use in cephalopods in the laboratory and aquaculture, at all life stages, requires research into their effects on growth and metabolism (Sykes et al., 2006; Navarro et al., 2014). There is debate about whether research into different diets falls within the remit of Directive 2010/63/EU (see Sykes et al., 2012) so the issues of concern are discussed here. Firstly, investigation of the effects of different diets is clearly "research" as the outcome is not known and an experimental approach is required to obtain the answer so does not come under the exempt category of "non-experimental agricultural practices" (Article 1, 5a). Secondly, the response of the animal to a novel experimental diet may not be immediately apparent so there is a potential that the animal may experience suffering, distress or lasting harm that exceeds the threshold for regulation. Until the novel diet is studied its effects on the animal cannot be fully assessed. Third, many studies are directed at identification of diets or environmental factors to improve survival of paralarvae in species such as $O$. vulgaris where mortality in aquaculture conditions from hatchling to the benthic phase is $\approx 100 \%$ in most of the studies and has changed little over 20 years (Villanueva, 1995). Note that the survival rate in the wild is not known so comparison with survival rates in laboratory condition is not possible. In studies of diet and environmental changes, mortality/survival rates are often used as one of the outcome measures. The aim of many paralarvae studies is to modify the diet, light or temperature to improve survival rates so mortality is a valid outcome measure. However, the severity classification of procedures would classify as "severe" toxicity testing where death is an end point or where there is a severe impairment of wellbeing or general condition (e.g., see paper by Feyjoo et al., 2011). The effect of a novel diet on survival cannot be predicted, so it is possible that the mortality may be either higher or lower than a current feeding regime. Whilst the degree of suffering which may be experienced by a paralarvae before death is not known, this discussion illustrates the regulatory challenges raised by the inclusion in Directive 2010/63/EU of cephalopods from the time of hatching.

\section{THE POTENTIAL IMPACT OF EXPERIMENTAL PROCEDURES ON THE CEPHALOPOD DIGESTIVE TRACT: ISSUES TO CONSIDER}

The potential impact of any experimental procedure on functionality of the digestive tract should be assessed as part of experimental planning. For investigators whose research is regulated by Directive 2010/63/EU (see below) a full assessment of the effects of an experimental investigation and assessment of the anticipated harms (to the animal) and potential benefits (of the answer to the research question) is an essential component of the application for authorization to the National Competent Authority. There have not been any formal studies on the effect of common procedures on the cephalopod digestive tract but below we comment on the most likely areas of concern to stimulate discussion and raise awareness of the issues. As for other issues discussed in this is overview the specific effects on the digestive tract of any intervention are likely to be affected by life stage and species.

\section{Anesthesia and Surgery}

A number of authors have commented that cephalopods recover rapidly from brief periods of general anesthesia, not usually involving surgery, with reports of food ingestion within 10-15 min of recovery anesthesia (Joll, 1977; Gonçalves et al., 2012). Food ingestion indicates an unimpaired attack response but does not necessarily imply that the digestive tract itself is unaffected by anesthesia, although it is suggestive. Whilst an anaesthetic may have an effect on the digestive tract by acting on the brain regions regulating the extrinsic innervation (visceral and sympathetic nerves; Young, 1967, 1971) a direct action on the digestive tract enteric nerves and muscle is also possible. For example, magnesium chloride is commonly used as an anesthetic agent in cephalopods (Fiorito et al., 2015) and in the isolated stomach and rectum of Loligo pealii it has an inhibitory effect on contractions and tone (Bacq, 1934). This inhibitory effect on the digestive tract is also consistent with the bradycardia and reduced stroke volume produced by magnesium chloride on the isolated systemic heart of O. vulgaris (Pugliese et al., 2016). For both the heart and digestive tract, the most likely mechanism by which magnesium chloride has its inhibitory effects is by interfering with calcium fluxes, but this requires confirmation by experiment. If digestive tract motility is inhibited for the duration 
of anesthesia it is likely that transit time will be prolonged until motility is normalized.

Surgery of the digestive tract and in particular lesions affecting the innervation (e.g., sympathetic nerves, gastric ganglia) will not surprisingly affect digestive tract function (e.g., Best and Wells, 1983) and hence impact the overall welfare of the animal. The impact of surgery outside the digestive tract on digestive tract functionality is not known, but if nociceptors are activated by the surgery (and analgesics are not provided) then neural and endocrine pathways regulating digestive tract function may be affected. Particular care needs to be taken to consider the likely effects of brain lesions on the ability of the animal to recognize, capture and ingest food and hence maintain normal metabolism. For example, O. vulgaris with lesioned anterior and posterior basal lobes are unable to feed themselves (Wells, 1978) so if there is a need to study these animals for more than a few days consideration will need to be given to how to ensure adequate nutrition to maintain health.

Currently, no analgesics have been used as part of the anesthesia protocol in cephalopods (Fiorito et al., 2015) but if potential substances are identified their pharmacological effects on the digestive tract should be ascertained. For example, opioid receptor agonists (e.g., morphine and synthetic derivatives) are used as an analgesic in mammals and are associated with constipation as a side effect, as amongst other actions they modulate transmission in the enteric nervous system to reduce transit (De Giorgio et al., 2007). Delta-opioid receptors have been identified in the digestive tract (Sha et al., 2012) and kappa-opioid receptors in O. vulgaris (Zarrella et al., 2015) but functional effects of their activation have not been investigated.

\section{Nociception and Stress}

In mammals, activation of somatic and visceral nociceptors inhibits gastric and intestinal motility contributing to an overall increase in oro-anal transit time via reflex and endocrine mechanisms. The nociceptors activate spinal and supra-spinal pathways modulating the sympathetic outflow to the digestive tract and the secretion of adrenaline from the adrenal medulla (Janig, 2013; Janig and Mclachlan, 2013).

Although mechano-nociceptors have been described in cephalopods (Crook et al., 2011, 2013, 2014; Alupay et al., 2014) in locations equivalent to somatic nociceptors in vertebrates their central projections are not known so we are unable to speculate if information from these nociceptors can influence the innervation to the digestive tract (visceral nerves and "sympathetic" nerves; Young, 1967). The existence of visceral nociceptors has not been investigated in cephalopods but there is structural and behavioral evidence for the existence of visceral afferents (Young, 1960, 1967). Nothing is known about the responses of the cephalopod digestive tract or the cardiovascular system (also modulated by the visceral nerves) to noxious stimuli but it would be surprising if neither system was affected. Non-painful, but unpleasant stressful stimuli such as those produced by restraint or hypoxia are also likely to affect digestive tract function via the innervation or secretion of "stress" hormones. For example, removal of E. cirrhosa from water for 5 min results in elevation of haemolymph dopamine levels (Malham et al., 2002), which could act on the crop where in vitro studies in $O$. vulgaris have shown dopamine to increase tone (Andrews and Tansey, 1983b) or alternatively the neurones in the gastric ganglion could be the target as there is histochemical evidence for its presence (Juorio, 1971) and hence dopamine receptors are likely to be present.

Both noxious and non-noxious but stressful external stimuli may also have both acute and chronic effects on the digestive tract via up or down regulation of genes in critical control locations such as the gastric ganglion. A diverse range of genes has been implicated in the response of octopus to environmental stressors (reviewed in Di Cosmo and Polese, 2016) but the biological effects of the gene products on the physiology of the digestive tract and its control requires investigation.

\section{Drug Administration}

A drug given systemically and being used as part of a research project to investigate one system (e.g., brain neurochemistry and effects on behavior) may also have unintended effects on control of food intake or the functioning of the digestive tract. For example, catecholamines are present in the brain (Tansey, 1980) and in neurones in the digestive tract and cardiovascular system of cephalopods (Andrews and Tansey, 1983a; Versen et al., 1999). Drugs used to investigate the role of catecholamines in brain functioning (e.g., learning and memory) either by depleting noradrenaline (e.g., reserpine; Tansey, 1980) or acting as competitive antagonists of adrenergic receptors (e.g., phentolamine; Versen et al., 1999) could affect digestive tract motility as noradrenaline stimulates contractile activity in the crop, stomach and intestine of O. vulgaris (Andrews and Tansey, 1983b). The potential problems are further illustrated by scopolamine (a nonselective muscarinic acetylcholine receptor antagonist) used to investigate memory recall in O. vulgaris (Fiorito et al., 1998) but as acetylcholine (receptor not characterized) has inhibitory effects on digestive tract motility (Andrews and Tansey, 1983b) this effect may be lost in animals treated with scopolamine, allowing excitatory effects to predominate. In neither paper using reserpine (Tansey, 1980) or scopolamine (Fiorito et al., 1998) were overt effects on the digestive tract reported but neither were they investigated explicitly and such effects may be subtle.

\section{Developmental Changes}

The publication of the genome of O. bimaculoides (Albertin et al., 2015) will be a major stimulus to cephalopod research. The intended and potential unintended effects of gene expression modifications (e.g., gene knock out, gene over expression) will need to be considered during project design and plans put in place to monitor adverse (or even beneficial) effects. Of particular concern would be modification to genes which may affect the development of the digestive tract including the neural control mechanisms. Exposure of recently spawned eggs to abnormal environmental condition can also produce developmental changes as demonstrated by an increase in malformations, early hatching and mortality in squid eggs exposed to sea water at $2^{\circ} \mathrm{C}$ above ambient (Rosa et al., 2012) or eggs of $O$. vulgaris exposed to an increase of $3^{\circ} \mathrm{C}$ (Repolho et al., 2014). 


\section{REDUCED FOOD INTAKE AS A HUMANE END-POINT IN PROCEDURES: WHAT ARE THE LIMITS?}

A humane end point is the earliest point at which a specific intervention must be made to end an animal's suffering and for each procedure under Directive 20110/63/EU. Humane endpoints are specified in the application to the National Competent Authority and describe the type of suffering that may occur, its magnitude and duration and these judgements contribute to the "prospective assessment of severity" of a procedure which is also indicated in application to the NCA (see below).

Typical interventions as the humane end point is reached could include: (i) removing the animal from the study; (ii) providing analgesia to alleviate pain or by treating other symptoms unrelated to the experimental outcomes but this is reliant on validated treatment being available and knowledge that they will not affect the primary experimental outcomes; (iii) humanely killing the animal and/or terminating the study.

There are three different types of study where the consequences and limits of reduced food intake need to be considered and these are discussed below to illustrate the issues. For completeness, we also include the special case (see below) of research involving senescent cephalopods.

\section{Investigation of the Effects of Food Deprivation}

There are a number of studies aimed at investigating the effects of different periods of food deprivation on a cephalopod (e.g., studies of O. vulgaris, Garcia-Garrido et al., 2010; S. officinalis studies of Lamarre et al., 2012, 2016; Speers-Roesch et al., 2016). In such studies the duration of food deprivation is predetermined and justified in terms of the anticipated harms to the animals vs. the potential scientific (or other) benefits of the study. Weight loss is an expected outcome of these studies, but if the protocol in the NCA submission has set a limit for the degree of weight loss (e.g., $20 \%$ over 14 days in adult O. vulgaris) then if this is exceeded, the animal would be removed from the study immediately. Humane end-points indicating that the food deprivation is having additional deleterious effects could include loss of the ability to maintain normal position in the water column, autophagy, skin lesions or an excessive reduction in the size of the digestive gland (e.g., measured by ultrasound; for a description of welfare monitoring parameters see Table 5 in Fiorito et al., 2015). If these signs were used as humane endpoints then, if observed, that animal would be removed from the study.

\section{Interventions Intended to Modify Food Intake}

There are a number of studies in which an intervention (e.g., an agonist with potential anorexic effects, administration of a pathogen or a nerve lesion such as gastric ganglion ablation) is intended to, or is likely to, modify food intake. In this type of study the issue is what limits should be placed on the reduced food intake? For example, for how many days should an animal be allowed to go without food before intervention? The duration will be related to the scientific outcomes; if the aim is to show that an intervention (e.g., investigating modulation of food intake by members of FMRFamide family; Walker et al., 2009) affects food intake then a period of $24 \mathrm{~h}$ may be sufficient to show an acute effect, but if there is a need to know the duration of any effect then longer may be needed. The duration of the study will be the minimum compatible with the scientific objectives assuming that the duration can be justified in the project application. Decisions about how long an animal should go without food or have reduced food intake before intervention should take into account metabolic studies (e.g., Garcia-Garrido et al., 2010; Lamarre et al., 2012, 2016; Speers-Roesch et al., 2016) but until more detailed information is available about the effects of food intake on physiology and behavior of the animals we would advise adoption of the precautionary principle in studies where food intake is likely to be affected.

\section{Procedures Affecting Food Intake as An Unintended Outcome}

In some cases experiments include a procedure that may affect food intake although this is not either the primary intent of the lesion or topic of study. In this case the reduced food intake is viewed as an "adverse" or "side" effect of the procedure. This type of study differs from food deprivation described above in that the effect on food intake is unintended rather than being a primary objective of the study but in both cases the issues relating to the duration of reduced food intake are the same.

\section{Senescence}

Markedly reduced or absent food intake is a well-known feature of senescent cephalopods occurring in post-mating adults and in females during egg-brooding (Anderson et al., 2002). Although this is a normal terminal life-stage in the wild, if the animal is being kept in the laboratory to study the physiology of senescence (e.g., how is appetitive drive inhibited?) then as the animal is likely to experience some suffering it arguably comes within the scope of Directive 2010/63/EU (see Smith et al., 2013, for discussion). As the reduction in food intake progresses the animals will rapidly pass through metabolic phases I, II described above in animals deprived of food and will probably spend the longest time in phase III until death ensues (Moltschaniwskyj and Carter, 2013). Studying senescence is further complicated because animals not only stop eating but may develop other symptoms such as cataracts, skin lesions and increased, but uncoordinated, locomotor activity (Anderson et al., 2002; Sykes et al., 2012; Sykes and Gestal, 2014) none of which can be alleviated. If studies of the digestive changes accompanying reproduction and senescence are to be investigated a critical question will be whether it is necessary to study the animal until death to answer the scientific question posed? We would argue that understanding the mechanism of food intake suppression only requires a relatively short period of study (e.g., a week) but if the topic of interest is whether the enteric nervous system shows signs of degeneration with age, as occurs in mammals (Hetz et al., 2014; Saffrey, 2014), then longer periods of study may be required. 


\section{RECOMMENDATIONS AND RESEARCH QUESTIONS TO ENHANCE CEPHALOPOD HEALTH AND WELFARE}

This review has drawn attention to the numerous close relationships between the normal physiological functioning of the digestive tract in cephalopods and their health and welfare. Although the relationships between normal digestive tract function, health and welfare may appear obvious, conforming with regulatory requirements (particularly Directive 2010/63/EU) necessitates developing a more evidence based approach to ensuring adequate nutrition and identification of biomarkers of health and welfare.

The text below summarizes some of the key points and areas which we consider require research.

(i) Reporting feeding regimes in publications is variable so a consistent approach should be adopted to include as a minimum: type of food; amount of food (weight or as a \% body weight); feeding frequency and time. This will facilitate meta-analysis of diets.

(ii) Cephalopods for research are frequently taken from the wild and may have been exposed to ingested toxins (e.g., domoic acid) and parasites (e.g., Aggregata); these are considered as potential confounding factors in research which may be unidentified prior to allocation to experimental groups. The impact of parasites and toxins on health and welfare requires research.

(iii) Techniques for non-invasive investigation of digestive tract physiology are required to enhance routine health and welfare assessment (for review see Ponte et al., 2017), to improve understanding of the effects of experimental interventions and also to develop humane end-point criteria for regulated procedures.

(iv) Little is known of relationships between behavior and digestive tract functionality in cephalopods. For example: would digestive tract obstruction result in behavioral change due to visceral nociceptor activation? What behavioral changes accompany food deprivation of different durations?

(v) Periods of food deprivation may be required for various types of research and we considered this in relation to knowledge of cephalopod metabolism and the regulatory threshold and prospective severity assessment; deprivation $>2 \mathrm{~d}$ is proposed to reach the threshold for regulation under Directive 2010/63/EU in the "mild" category and $>12 \mathrm{~d}$ would be "severe."

(vi) The potential negative impact of experimental interventions such as food deprivation, anesthesia (e.g., inhibition of smooth muscle contraction by magnesium chloride) and surgery, (e.g., brain lesion), pain (e.g., activation of nociceptors) and stress (e.g., weighing in air), drug administration (e.g., cholinergic and adrenergic receptor antagonist impacting digestive tract innervation) and genetic modification on the functioning of the digestive tract are considered from the perspective of animal welfare.

(vii) Research on the digestive tract physiology is needed to understand constraints of $O$. vulgaris aquaculture and in particular the maturation of function and control mechanisms (e.g., gastric ganglion) and changes occurring between the paralarvae and settlement phases where dietary changes occur and there are likely to be changes in the digestive tract microbiome.

(viii) Improved understanding of all aspects of the physiology of the digestive tract (food intake regulation, motility, secretion, absorption, neural, and endocrine control) in a diverse range of species will play a key role in ensuring optimal health and welfare of cephalopods in the laboratory, aquaculture and display aquaria.

Good animal welfare and good science are inextricably linked (see Hubrecht, 2014, for review). We hope that this paper will stimulate research on the digestive system which in addition to providing novel insights into the physiology will also enhance the welfare of cephalopods in both research and aquaculture.

\section{AUTHOR CONTRIBUTIONS}

AVS and EA are equal first authors. All authors contributed to the manuscript and drafted, edited and approved the final version of the manuscript.

\section{FUNDING}

EA's was supported by the OCTOWELF project (AGL 2013-49101-C2-1-R, Spanish Government). AVS was supported through Fundação para a Ciência e a Tecnologia (IF/00576/2014 contract and Plurennial funding to CCMARUID/Multi/04326/2013). This study was also supported through RITMARE Flagship Project (Italian Ministry of Education, University and Research-MIUR, and Stazione Zoologica Anton Dohrn-SZN) and a fellowship to GP. PLRA wishes to acknowledge that this review was written during the tenure of an honorary Research Fellowship at Stazione Zoologica Anton Dohrn Naples, Italy.

\section{ACKNOWLEDGMENTS}

PA would like to thank Dr. G. Fiorito (Head of the Department of Biology and Evolution of Marine Organisms, SZN) and the President of the Stazione Zoologica Anton Dohrn (SZN), Prof. Roberto Danovaro. This work benefited from networking activities carried out under the COST ACTION FA1301, and is considered a contribution to the COST (European Cooperation on Science and Technology) Action FA1301 "A network for improvement of cephalopod welfare and husbandry in research, aquaculture and fisheries" (http://www.cephsinaction.org/). 


\section{REFERENCES}

Agnisola, C., Castaldo, P., and Fiorito, G. (1996). Octopus vulgaris (Mollusca, Cephalopoda) as a model in behavioral pharmacology: a test of handling effects. Physiol. Behav. 59, 729-733. doi: 10.1016/0031-9384(95)02153-1

Albertin, C. B., Simakov, O., Mitros, T., Wang, Z. Y., Pungor, J. R., EdsingerGonzales, E., et al. (2015). The octopus genome and the evolution of cephalopod neural and morphological novelties. Nature 524, 220-224. doi: $10.1038 /$ nature 14668

Alupay, J. S., Hadjisolomou, S. P., and Crook, R. J. (2014). Arm injury produces long-term behavioral and neural hypersensitivity in octopus. Neurosci. Lett. 558, 137-142. doi: 10.1016/j.neulet.2013.11.002

Anderson, R. C., Wood, J. B., and Byrne, R. A. (2002). Octopus senescence: the beginning of the end. J. Appl. Animal Welf. Sci. 5, 275-283. doi: 10.1207/S15327604JAWS0504_02

Andrews, P. L. R., and Sanger, G. J. (2014). Nausea and the quest for the perfect anti-emetic. Eur. J. Pharmacol. 722, 108-121. doi: 10.1016/j.ejphar.2013.09.072

Andrews, P. L. R., and Tansey, E. M. (1983a). Aminergic innervation of the blood-vessels of Octopus vulgaris. Cell Tissue Res. 230, 229-232.

Andrews, P. L. R., and Tansey, E. M. (1983b). The digestive tract of Octopus vulgaris - the anatomy, physiology and pharmacology of the upper tract. $J$. Marine Biol. Assoc. U.K. 63, 109-134.

Ashley, P. J. (2007). Fish welfare: current issues in aquaculture. Appl. Anim. Behav. Sci. 104, 199-235. doi: 10.1016/j.applanim.2006.09.001

Bacq, Z. M. (1934). Recherches sur la physiologie du systéme nerveux autonome V. Reactions du ventricle median, des chromatophores et de divers organes isoles d'un mollusque cephalopode (Loligo pealeii) a l'adrenaline, l'acetylcholine, l'ergotamine, l'atropine et aux ions K,Ca et Mg. Arch. Int. Physiol. XXXVIII, $138-159$.

Barr, S., Laming, P. R., Dick, J. T. A., and Elwood, R. W. (2008). Nociception or pain in a decapod crustacean? Anim. Behav. 75, 745-751. doi: 10.1016/j.anbehav.2007.07.004

Bayne, K., and Würbel, H. (2014). The impact of environmental enrichment on the outcome variability and scientific validity of laboratory animal studies. Rev. Off. Int. Epizoot. 33, 273-280. doi: 10.20506/rst.33.1.2282

Berk, W., Teperman, J., Walton, K. D., Hirata, K., Sugimori, M., and Llinas, R. R. (2009). Oral administration of pharmacologically active substances to squid: a methodological description. Biol. Bull. 216, 1-6. doi: 10.1086/BBLv216n1p1

Best, E. M. H., and Wells, M. J. (1983). The control of digestion in octopus I: the anticupatory response and the effects of severing the nerves to the gut. Vie Milieu 33, 135-142.

Bidder, A. M. (1950). The digestive mechanism of the European squids Loligo vulgaris, Loligo forbesii, Alloteuthis media and Alloteutihis subulata. Q. J. Microsc. Sci. s3-91, 1-43.

Bidder, A. M. (1966). "Feeding and digestion in cephalopods," in Physiology of the Mollusca, eds K. M. Wilbur and C. M. Yonge (New York, NY: Academic Press Inc.), 97-124.

Boletzky, S. V. (1981). Réflexions sur les stratégies de reproduction chez les céphalopodes. Bull. Soc. Zool. France 106, 293-304.

Boletzky, S. V. (1986). Reproductive strategies in cephalopods: variation and flexibility of life-history patterns. Adv. Inverteb. Reprod. 4, 379-389.

Boletzky, S. V. (1994). Embryonic development of cephalopods at low temperatures. Antar. Sci. 6, 139-142. doi: 10.1017/S0954102094000210

Boletzky, S. V., and Villanueva, R. (2014). "Cephalopod biology," in Cephalopod Culture, eds J. Iglesias, L. Fuentes \& R. Villanueva. (Dordrecht: Springer), 3-16.

Boucaud-Camou, E., and Boucher-Rodoni, R. (1983). "Feeding and digestion in cephalopods," in The Mollusca - Physiology. Part 2, eds A. S. M. Saleuddin and K. M. Wilbur (New York, NY: Academic Press), 149-187.

Boucher-Rodoni, R., and Mangold, K. (1977). Experimental study of digestion in Octopus vulgaris (Cephalopoda: Octopoda). J. Zool. Lond. 183, 505-515. doi: 10.1111/j.1469-7998.1977.tb04202.x

Boucher-Rodoni, R., and Mangold, K. (1985). Ammonia excretion during feeding and starvation in Octopus vulgaris. Mar. Biol. 86, 193-197. doi: 10.1007/BF00399026

Castellanos-Martinez, S., Diz, A. P., Alvarez-Chaver, P., and Gestal, C. (2014). Proteomic characterization of the hemolymph of Octopus vulgaris infected by the protozoan parasite Aggregata octopiana. J. Proteomics 105, 151-163. doi: $10.1016 /$ j.jprot.2013.12.008
Castro, B. G., Dimarco, F. P., Derusha, R. H., and Lee, P. G. (1993). The effects of surimi and pelleted diets on the laboratory survival, growth, and feeding rate of the cuttlefish Sepia officialis L. J. Exp. Mar. Biol. Ecol. 170, 241-252. doi: 10.1016/0022-0981(93)90155-H

Castro, B. G., and Lee, P. G. (1994). The effects of semi-purified diets on growth and condition of Sepia officinalis L (Mollusca, Cephalopoda). Comparat. Biochem. Physiol. Physiol. 109, 1007-1016. doi: 10.1016/0300-9629(94)90250-X

Cerezo Valverde, J., and García, B. G. (2017). High feeding and growth rates in common octopus (Octopus vulgaris) fed formulated feeds with an improved amino acid profile and mixture of binders. Aquac. Res. 48, 3308-3319. doi: $10.1111 /$ are. 13157

Cooke, G. M., and Tonkins, B. M. (2015). Behavioural indicators of welfare exhibited by the common European cuttlefish (Sepia officinalis). J. Zoo Aquar. Res. 3, 157-162. doi: 10.19227/jzar.v3i4.142

Cornet, V., Henry, J., Corre, E., Le Corguille, G., Zanuttini, B., and ZatylnyGaudin, C. (2014). Dual role of the cuttlefish salivary proteome in defense and predation. J. Proteomics 108, 209-222. doi: 10.1016/j.jprot.2014.05.019

Correia, M., Palma, J., and Andrade, J. P. (2008a). Effects of live prey availability on growth and survival in the early stages of cuttlefish Sepia officinalis (Linnaeus, 1758) life cycle. Aquac. Res. 39, 33-40. doi: 10.1111/j.1365-2109.2007.01858.x

Correia, M., Palma, J., Kirakowski, T., and Andrade, J. P. (2008b). Effects of prey nutritional quality on the growth and survival of juvenile cuttlefish, Sepia officinalis (Linnaeus, 1758). Aquac. Res. 39, 869-876. doi: $10.1111 /$ j.1365-2109.2008.01940.x

Costa, P. M., Rodrigo, A. P., and Costa, M. H. (2014). Microstructural and histochemical advances on the digestive gland of the common cuttlefish, Sepia officinalis L. Zoomorphology 133, 59-69. doi: 10.1007/s00435-013-0201-8

Costa, P. R., and Pereira, J. (2010). Ontogenic differences in the concentration of domoic acid in the digestive gland of male and female Octopus vulgaris. Aquat. Biol. 9, 221-225. doi: 10.3354/ab00255

Crook, R. J., Hanlon, R. T., and Walters, E. T. (2013). Squid have nociceptors that display widespread long-term sensitization and spontaneous activity after bodily injury. J. Neurosci. 33, 10021-10026. doi: 10.1523/JNEUROSCI.0646-13.2013

Crook, R. J., Lewis, T., Hanlon, R. T., and Walters, E. T. (2011). Peripheral injury induces long-term sensitization of defensive responses to visual and tactile stimuli in the squid Loligo pealeii, Lesueur 1821. J. Exp. Biol. 214, 3173-3185. doi: 10.1242/jeb.058131

Crook, R. J., Dickson, K., Hanlon, R. T., and Walters, E. T. (2014). Nociceptive sensitization reduces predation risk. Curr. Biol. 24, 1121-1125. doi: 10.1016/j.cub.2014.03.043

Darmaillacq, A. S., Dickel, L., Chichery, M. P., Agin, V., and Chichery, R. (2004). Rapid taste aversion learning in adult cuttlefish, Sepia officinalis. Anim. Behav. 68, 1291-1298. doi: 10.1016/j.anbehav.2004.01.015

Darmaillacq, A. S., Lesimple, C., and Dickel, L. (2008). Embryonic visual learning in the cuttlefish, Sepia officinalis. Anim. Behav. 76, 131-134. doi: 10.1016/j.anbehav.2008.02.006

De Giorgio, R., Barbara, G., Furness, J. B., and Tonini, M. (2007). Novel therapeutic targets for enteric nervous system disorders. Trends Pharmacol. Sci. 28, 473-481. doi: 10.1016/j.tips.2007.08.003

Di Cosmo, A., and Polese, G. (2016). Neuroendocrine-immune systems response to environmental stressors in the cephalopod Octopus vulgaris. Front. Physiol. 7:434. doi: 10.3389/fphys.2016.00434

Domingues, P., Ferreira, A., Marquez, L., Andrade, J. P., Lopez, N., and Rosas, C. (2008). Growth, absorption and assimilation efficiency by mature cuttlefish (Sepia officinalis) fed with alternative and artificial diets. Aquac. Int. 16, 215-229. doi: 10.1007/s10499-007-9139-5

Domingues, P. M., Kingston, T., Sykes, A., and Andrade, J. P. (2001). Growth of young cuttlefish, Sepia officinalis (Linnaeus 1758) at the upper end of the biological distribution temperature range. Aquac. Res. 32, 923-930. doi: 10.1046/j.1365-2109.2001.00631.x

Estefanell, J., Socorro, J., Tuya, F., Izquierdo, M., and Roo, J. (2011). Growth, protein retention and biochemical composition in Octopus vulgaris fed on different diets based on crustaceans and aquaculture by-products. Aquaculture 322-323, 91-98. doi: 10.1016/j.aquaculture.2011.09.027

Council of the European Union (1998). Council Directive 98/58/EC of 20 July 1998 Concerning the Protection of Animals Kept for Farming Purposes. Strasbourg: Council of Europe. 
Council of the European Union (2009). Council Regulation (EC) No 1099/2009 of 24 September 2009 on the Protection of Animals at the Time of Killing. Brussels: Council of the European Union.

European Commission (2013). Examples to Illustrate the Process of Severity Classification, Day-to-Day Assessment and Actual Severity Assessment. Available online at: http://ec.europa.eu/environment/chemicals/lab_animals/interpretation_en.htm

European Parliament and Council of the European Union (2010). Directive 2010/63/EU of The European Parliament and of the Council of 22 September 2010 on the Protection of Animals used for Scientific Purposes. Brussels: European Commission.

European Parliament and Council of the European Union (2004). Regulation (EC) $N^{\circ}$ 882/2004 of the European Parliament and of the Council of 29 April 2004 on official Controls Performed to Ensure the Verification of Compliance with Feed and Food Law, Animal Health and Animal Welfare Rules. Strasbourg: Council of Europe.

Feyjoo, P., Riera, R., Felipe, B. C., Skalli, A., and Almansa, E. (2011). Tolerance responses to ammonia and nitrite in hatchlings paralarvae of Octopus vulgaris and its toxic effects on prey consumption rate and chromatophore activity. Aquac. Int. 19, 193-204. doi: 10.1007/s10499-010-9352-5

Fiorito, G., Affuso, A., Anderson, D. B., Basil, J., Bonnaud, L., Botta, G., et al. (2014). Cephalopods in neuroscience: regulations, research and the 3 Rs. Invert. Neurosci. 14, 13-36. doi: 10.1007/s10158-013-0165-x

Fiorito, G., Affuso, A., Basil, J., Cole, A., De Girolamo, P., D’angelo, L., et al. (2015). Guidelines for the care and welfare of cephalopods in research - a consensus based on an initiative by CephRes, FELASA and the Boyd Group. Lab. Anim. 49, 1-90. doi: 10.1177/0023677215580006

Fiorito, G., Agnisola, C., D’addio, M., Valanzano, A., and Calamandrei, G. (1998). Scopolamine impairs memory recall in Octopus vulgaris. Neurosci. Lett. 253, 87-90. doi: 10.1016/S0304-3940(98)00611-9

García-García, B., and Cerezo-Valverde, J. (2006). Optimal proportions of crabs and fish in diet for common octopus (Octopus vulgaris) ongrowing. Aquaculture 253, 502-511. doi: 10.1016/j.aquaculture.2005.04.055

García García, B., Valverde, J. C., Gómez, E., Hernández, M. D., and AguadoGiménez, F. (2011). Ammonia excretion of octopus (Octopus vulgaris) in relation to body weight and protein intake. Aquaculture 319, 162-167. doi: 10.1016/j.aquaculture.2011.06.017

Garcia-Garrido, S., Hachero-Cruzado, I., Garrido, D., Rosas, C., and Domingues, P. (2010). Lipid composition of the mantle and digestive gland of Octopus vulgaris juveniles (Cuvier, 1797) exposed to prolonged starvation. Aquac. Int. 18, 1223-1241. doi: 10.1007/s10499-010-9335-6

Gestal, C., Abollo, E., and Pascual, S. (2002a). Observations on associated histopathology with Aggregata octopiana infection (Protista: Apicomplexa) in Octopus vulgaris. Dis. Aquat. Org. 50, 45-49. doi: 10.3354/dao050045

Gestal, C., Páez De La Cadena, M., and Pascual, S. (2002b). Malabsorption syndrome observed in the common octopus Octopus vulgaris infected with Aggregata octopiana (Protista: Apicomplexa). Dis. Aquat. Org. 51, 61-65. doi: $10.3354 /$ dao051061

Gonçalves, R. A., Aragao, C., Frias, P. A., and Sykes, A. V. (2012). The use of different anaesthetics as welfare promoters during short-term human manipulation of European cuttlefish (Sepia officinalis) juveniles. Aquaculture 370, 130-135. doi: 10.1016/j.aquaculture.2012.10.014

Grimaldi, A. M., Belcari, P., Pagano, E., Cacialli, F., and Locatello, L. (2013). Immune responses of Octopus vulgaris (Mollusca: Cephalopoda) exposed to titanium dioxide nanoparticles. J. Exp. Mar. Biol. Ecol. 447, 123-127. doi: 10.1016/j.jembe.2013.02.018

Grosell, M., Farrell, A. P., and Colin, J. B. (2010). The Multifunctional Gut of Fish. Oxford, UK: Academic Press.

Hawkins, P., Dennison, N., Goodman, G., Hetherington, S., Llywelyn-Jones, S., Ryder, K., et al. (2011). Guidance on the severity classification of scientific procedures involving fish: report of a Working Group appointed by the Norwegian Consensus-Platform for the Replacement, Reduction and Refinement of animal experiments (Norecopa). Lab. Anim. 45, 219-224. doi: 10.1258/la.2011.010181

Hetz, S., Acikgoez, A., Moll, C., Jahnke, H.-G., Robitzki, A. A., Metzger, R., et al. (2014). Age-related gene expression analysis in enteric ganglia of human colon after laser microdissection. Front. Aging Neurosci. 6:276. doi: $10.3389 /$ fnagi.2014.00276
Hobson, K. A., and Cherel, Y. (2006). Isotopic reconstruction of marine food webs using cephalopod beaks: new insight from captively raised Sepia officinalis. Can. J. Zool. Revue Canad. De Zool. 84, 766-770. doi: 10.1139/z06-049

Hoving, H. J. T., and Robison, B. H. (2012). Vampire squid: detritivores in the oxygen minimum zone. Proc. R. Soc. B Biol. Sci. 279, 4559-4567. doi: 10.1098/rspb.2012.1357

Hubrecht, R. C. (2014). The Welfare of Animals Used in Research: Practice and Ethics. Oxford: Wiley Blackwell.

Huntingford, F. (2008). "Animal welfare in aquaculture," in Aquaculture, Innovation and Social Transformation, eds K. Culver and D. Castle (Dordrecht: Springer Netherlands), 21-33.

Iglesias, J., and Fuentes, L. (2014). "Octopus vulgaris. Paralarval culture," in Cephalopod Culture, eds J. Iglesias, L. Fuentes, and R. Villanueva (Dordrecht: Springer), 427-450.

Iglesias, J., Fuentes, L., and Villanueva, R. (2014). Cephalopod Culture. Dordrecht: Springer.

Janig, W. (2013). "Pain and the sympathetic nervous system," in Autonomic Failure, eds C. J. Mathias and R. Bannister (Oxford: Oxford University Press), 236-246.

Janig, W., and Mclachlan, E. M. (2013). "Neurobiology of the autonomic nervous system," in Autonomic Failure, eds C. J. Mathias and R. Bannister (Oxford: Oxford University Press), 21-34

Joll, L. M. (1977). Growth and food intake of Octopus tetricus (Mollusca:Cephalopoda) in aquaria. Aus, J. Marine Freshw. Res. 28, 43-56.

Juorio, A. V. (1971). Catecholamines and 5-hydroxytryptamine in nervous tissue of cephalopods. J. Physiol. Lond. 216, 213-226. doi: 10.1113/jphysiol.1971.sp009519

Lamarre, S. G., Ditlecadet, D., Mckenzie, D. J., Bonnaud, L., and Driedzic, W. R. (2012). Mechanisms of protein degradation in mantle muscle and proposed gill remodeling in starved Sepia officinalis. Am. J. Physiol. Regul. Integr. Compar. Physiol. 303, R427-R437. doi: 10.1152/ajpregu.00077.2012

Lamarre, S. G., Maccormack, T. J., Sykes, A. V., Hall, J. R., Speers-Roesch, B., Callaghan, N. I., et al. (2016). Metabolic rate and rates of protein turnover in food deprived cuttlefish, Sepia officinalis (Linnaeus 1758). Am. J. Physiol. Regul. Integr. Compar. Physiol. 310, R1160-R1168. doi: 10.1152/ajpregu.00459.2015

Lefebvre, K. A., and Robertson, A. (2010). Domoic acid and human exposure risks: a review. Toxicon 56, 218-230. doi: 10.1016/j.toxicon.2009. 05.034

Linares, M., Caamal-Monsreal, C., Olivares, A., Sanchez, A., Rodriguez, S., Zuniga, O., et al. (2015). Timing of digestion, absorption and assimilation in octopus species from tropical (Octopus maya) and subtropical-temperate (O. mimus) ecosystems. Aquat. Biol. 24, 127-140. doi: 10.3354/ab00642

Lopes, V. M., Baptista, M., Repolho, T., Rosa, R., and Costa, P. R. (2014). Uptake, transfer and elimination kinetics of paralytic shellfish toxins in common octopus (Octopus vulgaris). Aquat. Toxicol. 146, 205-211. doi: 10.1016/j.aquatox.2013.11.011

Lopes, V. M., Lopes, A. R., Costa, P., and Rosa, R. (2013). Cephalopods as vectors of harmful algal bloom toxins in marine food webs. Mar. Drugs 11, 3381-3409. doi: $10.3390 / \mathrm{md} 11093381$

Malham, S. K., Lacoste, A., Gelebart, F., Cueff, A., and Poulet, S. A. (2002). A first insight into stress-induced neuroendocrine and immune changes in the octopus Eledone cirrhosa. Aquat. Living Res. 15, 187-192. doi: 10.1016/S0990-7440(02)01173-7

Mancuso, M., Giordano, D., Genovese, L., Denaro, M. G., and Caruso, G. (2014). Study of digestive enzymes in wild specimens of Sepia officinalis (Linnaeus, 1758) and Octopus vulgaris (Cuvier, 1797). Cah. Biol. Mar. 55, 445-452.

Mangold, K., and Bidder, A. M. (1989). "L'appareil digestif et la digestion," in Traite de Zoologie, ed K. Mangold (Paris: Masson), 321-373.

Martínez, R., Gallardo, P., Pascual, C., Navarro, J., Sanchez, A., Caamal-Monsreal, C., et al. (2014). Growth, survival and physiological condition of Octopus maya when fed a successful formulated diet. Aquaculture 426, 310-317. doi: 10.1016/j.aquaculture.2014.02.005

Martínez, R., López-Ripoll, E., Avila-Poveda, O. H., Santos-Ricalde, R., Mascaró, M., and Rosas, C. (2011a). Cytological ontogeny of the digestive gland in posthatching Octopus maya, and cytological background of digestion in juveniles. Aquat. Biol. 11, 249-261. doi: 10.3354/ab00305

Martínez, R., Santos, R., Alvarez, A., Cuzon, G., Arena, L., Mascaro, M., et al. (2011b). Partial characterization of hepatopancreatic and extracellular digestive 
proteinases of wild and cultivated Octopus maya. Aqua. Int. 19, 445-457. doi:10.1007/s10499-010-9360-5

Martínez, R., Santos, R., Mascaró, M., Canseco, L., Caamal-Monsreal, C., and Rosas, C. (2012). Digestive dynamics during chyme formation of Octopus maya (Mollusca, Cephalopoda). Aquac. Res. 43, 1119-1126. doi: 10.1111/j.1365-2109.2011.02915.x

Martins, C., Galhardo, L., Noble, C., Damsgård, B., Spedicato, M., Zupa, W., et al. (2012). Behavioural indicators of welfare in farmed fish. Fish Physiol. Biochem. 38, 17-41. doi: 10.1007/s10695-011-9518-8

Matzner, H., Gutfreund, Y., and Hochner, B. (2000). Neuromuscular system of the flexible arm of the octopus: physiological characterization. Am. Physiol. Soc. 83, 1315-1328.

Messenger, J. B. (1996). Neurotransmitters of cephalopods. Inver. Neurosci. 2, 95-114. doi: 10.1007/BF02214113

Moguel, C., Mascaro, M., Avila-Poveda, O. H., Caamal-Monsreal, C., Sanchez, A., Pascual, C., et al. (2010). Morphological, physiological and behavioral changes during post-hatching development of Octopus maya (Mollusca: Cephalopoda) with special focus on the digestive system. Aquat. Biol. 9, 35-48. doi: 10.3354/ab00234

Moltschaniwskyj, M. A., and Carter, C. G. (2013). The adaptive response of protein turnover to the energetic demands of reproduction in a cephalopod. Physiol. Biochem. Zool. 86, 119-126. doi: 10.1086/667799

Moltschaniwskyj, N., and Johnston, D. (2006). Evidence that lipid can be digested by the dumpling squid Euprymna tasmanica, but is not stored in the digestive gland. Mar. Biol. 149, 565-572. doi: 10.1007/s00227-006-0246-z

Morillo-Velarde, P. S., Cerezo Valverde, J., and Garcia-Garcia, B. (2015). Utilization of diets with different fish oil content in common octopus (Octopus vulgaris Cuvier, 1797) and resulting changes in its biochemical composition. Aquac. Res. 46, 2871-2884. doi: 10.1111/are.12439

Näslund, J., and Johnsson, J. I. (2016). Environmental enrichment for fish in captive environments: effects of physical structures and substrates. Fish Fish. 17, 1-30. doi: 10.1111/faf. 12088

Navarro, J. C., Monroig, Ó., and Sykes, A. V. (2014). "Nutrition as a key factor for cephalopod aquaculture," in Cephalopod Culture, eds J. Iglesias, L. Fuentes, and R. Villanueva (Dordrecht: Springer), 77-95.

Navarro, J. C., and Villanueva, R. (2000). Lipid and fatty acid composition of early stages of cephalopods: an approach to their lipid requirements. Aquaculture 183, 161-177. doi: 10.1016/S0044-8486(99)00290-2

Nixon, M. (1969). The time and frequency of responses by Octopus vulgaris to an automatic food dispenser. J. Zool. Lond. 158, 475-483. doi: 10.1111/j.1469-7998.1969.tb02163.x

O’dor, R. K., Mangold, K., Boucher-Rodoni, R., Wells, M. J., and Wells, J. (1984). Nutrient absorption, storage and remobilization in Octopus vulgaris. Marine Behav. Physiol. 11, 239-258. doi: 10.1080/10236248409387049

Pech-Puch, D., Cruz-López, H., Canche-Ek, C., Campos-Espinosa, G., García, E., Mascaro, M., et al. (2016). Chemical tools of Octopus maya during crab predation are also active on conspecifics. PLOS ONE 11:e0148922. doi: 10.1371/journal.pone.0148922

Pugliese, C., Mazza, R., Andrews, P. L. R., Cerra, M. C., Fiorito, G., and Gattuso, A. (2016). Effect of different formulations of magnesium chloride used as anesthetic agents on the performance of the isolated heart of Octopus vulgaris. Front. Physiol. 7:610. doi: 10.3389/fphys.2016.00610

Pulido, O. (2008). Domoic acid toxicologic pathology: a review. Mar. Drugs 6, 180-219. doi: 10.3390/md6020180

Quintana, D., Marquez, L., Arevalo, J. R., Lorenzo, A., and Almansa, E. (2015). Relationships between spawn quality and biochemical composition of eggs and hatchlings of Octopus vulgaris under different parental diets. Aquaculture 446, 206-216. doi: 10.1016/j.aquaculture.2015. 04.023

Quintela, J., and Andrade, J. P. (2002a). Diel feeding rhythms, daily ration and gastric evacuation rates of Sepia officinalis in the Ria Formosa lagoon (south Portugal). Bull. Mar. Sci. 71, 665-680.

Quintela, J., and Andrade, J. P. (2002b). Effects of temperature on gastric evacuation rates in Sepia officinalis (Linnaeus, 1758) in laboratory conditions. Bull. Mar. Sci. 71, 681-689.

Regueira, M., Guerra, Á., Fernández-Jardón, C. M., and González, Á. F. (2017). Diet of the horned octopus Eledone cirrhosa in Atlantic Iberian waters: ontogenetic and environmental factors affecting prey ingestion. Hydrobiologia 785, 159-171. doi: 10.1007/s10750-016-2916-2

Ponte, G., Sykes, A. V., Cooke, G. M., Almansa, E., and Andrews, P. L. R. (2017). The digestive tract of cephalopods: toward non-invasive in vivo monitoring of its physiology. Front. Physiol. 8:403. doi: 10.3389/fphys.2017.00403

Repolho, T., Baptista, M., Pimentel, M. S., Dionisio, G., Trubenbach, K., Lopes, V. M., et al. (2014). Developmental and physiological challenges of octopus (Octopus vulgaris) early life stages under ocean warming. J. Comp. Physiol. B Biochem. Syst. Environ. Physiol. 184, 55-64. doi: 10.1007/s00360-013-0783-y

Rocha, F., Guerra, A., and Gonzalez, A. F. (2001). A review of reproductive strategies in cephalopods. Biol. Rev. 76, 291-304. doi: $10.1017 /$ S1464793101005681

Rønnestad, I., Yúfera, M., Ueberschär, B., Ribeiro, L., Sæle, Ø., and Boglione, C. (2013). Feeding behaviour and digestive physiology in larval fish: current knowledge, and gaps and bottlenecks in research. Rev. Aquac. 5, S59-S98. doi: $10.1111 /$ raq. 12010

Rosa, R., Pimentel, M. S., Boavida-Portugal, J., Teixeira, T., Trübenbach, K., and Diniz, M. (2012). Ocean warming enhances malformations, premature hatching, metabolic suppression and oxidative stress in the early life stages of a keystone squid. PLoS ONE 7:e38282. doi: 10.1371/journal.pone.0038282

Rosas, C., Cuzon, G., Pascual, C., Gaxiola, G., Chay, D., Lopez, N., et al. (2007). Energy balance of Octopus maya fed crab or an artificial diet. Mar. Biol. 152, 371-381. doi: 10.1007/s00227-007-0692-2

Rosas, C., Valero, A., Caamal-Monsreal, C., Uriarte, I., Farias, A., Gallardo, P., et al. (2013). Effects of dietary protein sources on growth, survival and digestive capacity of Octopus maya juveniles (Mollusca: Cephalopoda). Aquac. Res. 44, 1029-1044. doi: 10.1111/j.1365-2109.2012.03107.x

Ruth, P., Schipp, R., and Arnold, J. M. (1999). Organization and function of the midgut glands of Nautilus pompilius L. and Nautilus macromphalus SOW. (Cephalopoda, Tetrabranchiata). Zool. Anal. Complex Sys. 102, 196-211.

Saffrey, M. J. (2014). Aging of the mammalian gastrointestinal tract: a complex organ system. Age 36:9603. doi: 10.1007/s11357-11013-19603-11352

Scheel, D., Leite, T., Mather, J., and Langford, K. (2016). Diversity in the diet of the predator Octopus cyanea in the coral reef system of Moorea, French Polynesia. J. Natl. Hist. 1-19. doi: 10.1080/00222933.2016.1244298

Semmens, J. M., Pecl, G. T., Villanueva, R., Jouffre, D., Sobrino, I., Wood, J. B., et al. (2004). Understanding octopus growth: patterns, variability and physiology. Marine Freshw. Res. 55, 367-377. doi: 10.1071/MF03155

Sha, A., Sun, H., and Wang, Y. (2012). Immunohistochemical study of leucineenkephalin and delta opioid receptor in mantles and feet of the octopus Octopus ocellatus Gray. Int. J. Pept. Res. Ther. 18, 71-76. doi: 10.1007/s10989-011-9280-x

Smith, J. A., Andrews, P. L. R., Hawkins, P., Louhimies, S., Ponte, G., and Dickel, L. (2013). Cephalopod research and EU Directive 2010/63/EU: requirements, impacts and ethical review. J. Exp. Mar. Biol. Ecol. 447, 31-45. doi: 10.1016/j.jembe.2013.02.009

Sneddon, L. U. (2015). Pain in aquatic animals. J. Exp. Biol. 218, 967-976. doi: $10.1242 /$ jeb.088823

Speers-Roesch, B., Callaghan, N. I., Maccormack, T. J., Lamarre, S. G., Sykes, A. V., and Driedzic, W. R. (2016). Enzymatic capacities of metabolic fuel use in cuttlefish (Sepia officinalis) and responses to food deprivation: insight into the metabolic organization and starvation survival strategy of cephalopods. J. Comp. Physiol. B 186, 711-725. doi: 10.1007/s00360-016-0991-3

Stevens, C. E. (1988). Comparative Physiology of the Vertebrate Digestive System. Cambridge; New York, NY: Cambridge University Press.

Sykes, A. V., Baptista, F. D., Gonçalves, R. A., and Andrade, J. P. (2012). Directive 2010/63/EU on animal welfare: a review on the existing scientific knowledge and implications in cephalopod aquaculture research. Rev. Aquac. 4, 142-162. doi: 10.1111/j.1753-5131.2012.01070.x

Sykes, A. V., Domingues, P. M., Correia, M., and Andrade, J. P. (2006). Cuttlefish culture - State of the art and future trends. Vie et Milieu 56, 129-137.

Sykes, A. V., and Gestal, C. (2014). "Welfare and diseases under culture conditions," in Cephalopod Culture, eds J. Iglesias, L. Fuentes, and R. Villanueva (Dordrecht: Springer), 97-112.

Sykes, A. V., Gonçalves, R. A., and Andrade, J. P. (2013). Early weaning of cuttlefish (Sepia officinalis, L.) with frozen grass shrimp (Palaemonetes varians) from the first day after hatching. Aquac. Res. 44, 1815-1823. doi: 10.1111/j.1365-2109.2012.03186.x 
Sykes, A. V., Quintana, D., and Andrade, J. P. (2014). The effects of light intensity on growth and survival of cuttlefish (Sepia officinalis, Linnaeus 1758) hatchlings and juveniles. Aquac. Res. 45, 2032-2040. doi: 10.1111/are.12150

Tansey, E. M. (1980). Aminergic fluorescence in the cephalopod brain. Philos. Trans. R. Soc. Lond B Biol. Sci. 291, 127-145. doi: 10.1098/rstb.1980.0129

Tressler, J., Maddox, F., Goodwin, E., Zhang, Z. B., and Tublitz, N. J. (2014). Arm regeneration in two species of cuttlefish Sepia officinalis and Sepia pharaonis. Inver. Neurosci. 14, 37-49. doi: 10.1007/s10158-013-0159-8

Versen, B., Gokorsch, S., Fiedler, A., and Schipp, R. (1999). Monoamines and the isolated auricle of Sepia officinalis: are there beta-like receptors in the heart of a cephalopod? J. Exp. Biol. 202, 1067-1079.

Vidal, E. A. G., Villanueva, R., Andrade, J. P., Gleadail, I. G., Iglesias, J., Koueta, N., et al. (2014). Cephalopod culture: current status of main biological models and research priorities. Adv. Cephal. Sci. Biol. Ecol. Cultiv. Fish. 67, 1-98. doi: 10.1016/b978-0-12-800287-2.00001-9

Villanueva, R. (1995). Experimental rearing and growth of planktonic Octopus vulgaris from hatching to settlement. Can. J. Fish. Aquat. Sci. 52, 2639-2650. doi: 10.1139/f95-853

Villanueva, R., Koueta, N., Riba, J., and Boucaud-Camou, E. (2002). Growth and proteolytic activity of Octopus vulgaris paralarvae with different food rations during first feeding, using Artemia nauplii and compound diets. Aquaculture 205, 269-286. doi: 10.1016/S0044-8486(01)00678-0

Villanueva, R., Sykes, A. V., Vidal, É. A. G., Rosas, C., Nabhitabhata, J., Fuentes, L., et al. (2014). "Current status and future challenges in cephalopod culture," in Cephalopod Culture, eds J. Iglesias, L. Fuentes and R. Villanueva (Dordrecht: Springer), 479-489.

Villegas, E. J. A., Ceballos-Vázquez, B. P., Markaida, U., Abitia-Cárdenas, A., Medina-López, M. A., and Arellano-Martínez, M. (2014). Diet of Octopus bimaculatus Verril, 1883 (Cephalopoda: Octopodidae) in Bahía De Los Ángeles, Gulf of California. J. Shellfish Res. 33, 305-314. doi: 10.2983/035.033.0129

Visciano, P., Schirone, M., Berti, M., Milandri, A., Tofalo, R., and Suzzi, G. (2016). Marine biotoxins: occurrence, toxicity, regulatory limits and reference methods. Front. Microbiol. 7:1051. doi: 10.3389/fmicb.2016.01051

Vonk, H. J. (1962). Emulgators in the digestive fluids of invertebrates. Arch. Int. Physiol. Biochim. 70, 67-85. doi: 10.3109/13813456209092841

Walker, J. J., Longo, N., and Bitterman, M. E. (1970). The octopus in the laboratory. Handling, maintenance, training. Behav. Res. Methods Instrument. 2, 15-18. doi: 10.3758/BF03205718

Walker, R. J., Papaioannou, S., and Holden-Dye, L. (2009). A review of FMRFamide- and RFamide-like peptides in metazoa. Inver. Neurosci. 9, 111-153. doi: 10.1007/s10158-010-0097-7

Wearmouth, V. J., Durkin, O. C., Bloor, I. S. M., Mchugh, M. J., Rundle, J., and Sims, D. W. (2013). A method for long-term electronic tagging and tracking of juvenile and adult European common cuttlefish Sepia officinalis. J. Exp. Mar. Biol. Ecol. 447, 149-155. doi: 10.1016/j.jembe.2013.02.023

Wells, M. J. (1978). Octopus: Physiology and Behaviour of an Advanced Invertebrate. London: Chapman and Hall, Ltd.

Wells, M. J., O'dor, R. K., Mangold, K., and Wells, J. (1983). Diurnal changes in activity and metabolic rate in Octopus vulgaris. Mar. Behav. Physiol. 9, 275-287. doi: 10.1080/10236248309378598

Westermann, B., Beuerlein, K., Ruth, P., and Schipp, R. (2000). Tracer studies of food absorption in the digestive tract of Nautilus pompilius (Cephalopoda,
Tetrabranchiata). Cell Tissue Res. 300, 173-179. doi: 10.1007/s0044100 50058

Westermann, B., Ruth, P., Litzlbauer, H. D., Beck, I., Beuerlein, K., Schmidtberg, H., et al. (2002). The digestive tract of Nautilus pompilius (Cephalopoda, Tetrabranchiata): an X-ray analytical and computational tomography study on the living animal. J. Exper. Biol. 205, 1617-1624.

Westermann, B., and Schipp, R. (1998a). Cytological and enzyme-histochemical investigations on the digestive organs of Nautilus pompilius (Cephalopoda, Tetrabranchiata). Cell Tissue Res. 293, 327-336.

Westermann, B., and Schipp, R. (1998b). Morphology and histology of the digestive tract of Nautilus pompilius and Nautilus macromphalus (Cephalopoda, Tetrabranchiata). Zoomorphology 117, 237-245.

Westermann, B., and Schipp, R. (1999). Cytobiological investigation on the digestive organs of Nautilus pompilius L. (Cephalopoda, Tetrabranchiata). Vienna Ber. Geol. Bundesanst 46:119.

Yacob, J., Lewis, A. C., Gosling, A., St Hilaire, D. H. J., Tesar, L., Mcrae, M., et al. (2011). Principles underlying chromatophore addition during maturation in the European cuttlefish, Sepia officinalis. J. Exper. Biol. 214, 3423-3432. doi: 10.1242/jeb.055251

Yasumuro, H., and Ikeda, Y. (2016). Environmental enrichment accelerates the ontogeny of cryptic behavior in Pharaoh cuttlefish (Sepia pharaonis). Zool. Sci. 33, 255-265. doi: 10.2108/zs150197

Young, J. Z. (1960). Unit processes in the formation of representations in the memory of octopus. Proc. R. Soc. Lond. B Biol. Sci. 153, 1-17. doi: $10.1098 / \mathrm{rspb} .1960 .0084$

Young, J. Z. (1967). The visceral nerves of octopus. Philos. Trans. R. Soc. Lond. B Biol. Sci. 253, 1-22. doi: 10.1098/rstb.1967.0032

Young, J. Z. (1971). The Anatomy of the Nervous System of Octopus vulgaris. Oxford: Clarendon Press.

Young, R. E., and Harman, R. F. (1988). "Larva," "paralarva" and "subadult" in cephalopod terminology. Malacologia 29, 201-2017.

Yúfera, M., and Darias, M. J. (2007). The onset of exogenous feeding in marine fish larvae. Aquaculture 268, 53-63. doi: 10.1016/j.aquaculture.2007. 04.050

Zambonino-Infante, J. L., and Cahu, C. L. (2001). Ontogeny of the gastrointestinal tract of marine fish larvae. Comp. Biochem. Physiol. 130C, 447-487. doi: 10.1016/s1532-0456(01)00274-5

Zarrella, I., Ponte, G., Baldascino, E., and Fiorito, G. (2015). Learning and memory in Octopus vulgaris: a case of biological plasticity. Curr. Opin. Neurobiol. 35, 74-79. doi: 10.1016/j.conb.2015.06.012

Conflict of Interest Statement: The authors declare that the research was conducted in the absence of any commercial or financial relationships that could be construed as a potential conflict of interest.

Copyright (c) 2017 Sykes, Almansa, Cooke, Ponte and Andrews. This is an open-access article distributed under the terms of the Creative Commons Attribution License (CC $B Y)$. The use, distribution or reproduction in other forums is permitted, provided the original author(s) or licensor are credited and that the original publication in this journal is cited, in accordance with accepted academic practice. No use, distribution or reproduction is permitted which does not comply with these terms. 